\title{
Molecular Structure, Infrared Spectra, Photochemistry, and Thermal Properties of 1-Methylhydantoin
}

\author{
Bernardo A. Nogueira, ${ }^{\dagger}$ Gulce O. Ildiz, ${ }^{\dagger \dagger}$ João Canotilho, $^{\dagger, \S}$ M. Ermelinda S. Eusébio, ${ }^{\dagger}$ and Rui Fausto ${ }^{*}{ }^{\dagger}$ \\ ${ }^{\dagger}$ Department of Chemistry, University of Coimbra, P-3004-535, Coimbra, Portugal \\ ${ }^{\ddagger}$ Faculty of Sciences and Letters, Department of Physics, Istanbul Kultur University, Atakoy Campus, Bakirkoy 34156, Istanbul, \\ Turkey \\ ${ }^{\S}$ Faculty of Pharmacy, University of Coimbra, Coimbra, Portugal
}

\section{Supporting Information}

ABSTRACT: The structural, vibrational, and photochemical study of 1-methylhydantoin (1-MH, $\mathrm{C}_{4} \mathrm{H}_{6} \mathrm{~N}_{2} \mathrm{O}_{2}$ ) was undertaken by matrix isolation infrared spectroscopy (in argon matrix; $10 \mathrm{~K}$ ), complemented by quantum chemical calculations performed at the DFT(B3LYP)/6-311++G(d,p) level of approximation. The theoretical calculations yielded the $C_{s}$ symmetry structure, with planar heavy atom skeleton, as the minimum energy structure on the potential energy surface of the molecule. The electronic structure of this minimum energy structure of $1-\mathrm{MH}$ was then studied in detail by means of the natural bond orbital (NBO) and atoms in molecules (AIM) approaches, allowing for the elucidation of specific characteristics of the molecule's $\sigma$ and $\pi$ electronic systems. The infrared spectrum of the matrix-isolated 1-MH was fully assigned, also with the help of the theoretically predicted spectrum of the compound, and its UV-induced unimolecular photochemistry $(\lambda \geq 230 \mathrm{~nm})$ was investigated. The compound was found to fragment to CO, isocyanic acid, methylenimine, and $\mathrm{N}$-methyl-methylenimine. Finally, a thermal behavior investigation on 1-MH samples was carried out using infrared spectroscopy (10 K until melting), differential scanning calorimetry and polarized light thermal microscopy. A new polymorph of 1-MH was identified. The IR spectra of the different observed phases were recorded and interpreted.

\section{INTRODUCTION}

Hydantoins are heterocyclic organic compounds that derive from imidazolidine, with two carbonyl groups bonded in C2 and $\mathrm{C} 4$ positions; substituents can be present in the remaining atoms of the ring ( C5, N1, or N3). Hydantoins exhibit relevant physiological activities, for example as anticonvulsive, antiepileptic, anti-inflammatory, and anticancer drugs. ${ }^{1-6}$ The use of substituted hydantoins for the treatment of HIV-1 has also been suggested. ${ }^{7,8}$ In spite of the practical relevance of hydantoins, studies on the electronic structure, spectroscopic properties and photochemistry of this type of compounds are rather scarce. In fact, most of the reported studies on hydantoins deal with the determination of their crystal structures and the investigation of chirallity effects in the solid state (asymmetrically substituted hydantoins at C5 are enantiomeric). ${ }^{9-15}$

We have recently investigated the parent hydantoin $\left(\mathrm{C}_{3} \mathrm{H}_{4} \mathrm{~N}_{2} \mathrm{O}_{2}\right){ }^{16,17}$ Monomers of the compound were isolated in an argon matrix at $10 \mathrm{~K}$ and their structure, vibrational properties and unimolecular photochemistry studied by infrared spectroscopy, complemented by quantum chemical calculations. ${ }^{17}$ It was shown that the $C_{s}$ symmetry structure corresponds to the experimentally relevant form of the isolated hydantoin molecule. In the crystalline state (monoclinic $\mathrm{C} 2 / c$; $Z=8),{ }^{18}$ hydantoin molecules are linked by $\mathrm{N}-\mathrm{H} \cdots \mathrm{O}$ hydrogen bonds, forming chains where each molecule is connected to its two neighbors by a total of four H-bonds, the average enthalpy per $\mathrm{H}$-bond and $r(\mathrm{~N} \cdots \mathrm{O}) \mathrm{H}$-bond distance amounting to $-11.2 \mathrm{~kJ} \mathrm{~mol}^{-1}$ and $0.288 \mathrm{~nm}$, respectively. ${ }^{17,18}$ Upon UV-irradiation $(\lambda=230 \mathrm{~nm})$ of matrix-isolated hydantoin, photochemical transformation of the compound was observed, leading to formation of isocyanic acid (HNCO), carbon monoxide and methylenimine $\left(\mathrm{H}_{2} \mathrm{C}=\mathrm{NH}\right) .{ }^{17} \mathrm{H}$ bonded dimers of the compound have also been theoretically investigated ${ }^{16}$ and simple correlations extracted which relate the shifts in the $\mathrm{NH}$ stretching and bending modes with H-bond formation.

The present study is focused on the detailed characterization of the electronic structure of 1-methylhydantoin molecule (1$\mathrm{MH}$; Scheme 1), in particular the detailed investigation of the $\sigma$ and $\pi$ electronic systems of the molecule in the ground electronic state, interpretation of its infrared spectrum, and

Received: May 30, 2014

Revised: July 15, 2014

Published: July 16, 2014 
Scheme 1. 1-Methylhydantoin Molecule, with Atom Numbering

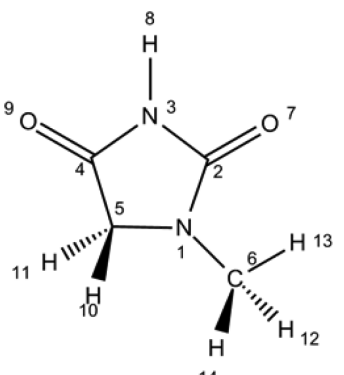

study of its photochemistry. 1-Methylhydantoin is one of the smallest and structurally simplest substituted hydantoins, bearing a single methyl substituent at N1. Substituted hydantoins at the nitrogen atoms have been shown to induce growth inhibition followed by apoptosis in leukemia cells, and their cytotoxity to be substantially influenced by the nature of the substituents. ${ }^{2,3}$ The knowledge of its structural, vibrational and photochemical properties is then relevant to the general structural characterization of more complex N1-substituted hydantoins, and understanding their photochemical reactivity (which can be expected to be more complex than for the nonsusbtituted parent compound), and biological way of action. The selected experimental technique was matrix isolation infrared spectroscopy, complemented by quantum chemical calculations performed at the DFT(B3LYP) level of approximation with the split-valence triple- $\zeta$, augmented with diffuse and polarization functions, $6-311++G(d, p)$ basis set.

The present investigation also included the thermal study of neat 1-methylhydantoin, within a wide temperature range (from $10 \mathrm{~K}$ to melting), using different experimental techniques (infrared spectroscopy, differential scanning calorimetry, polarized light thermomicroscopy and X-ray powder diffraction). A crystalline structure of $1-\mathrm{MH}$ was recently solved by $\mathrm{X}$ ray single crystal diffraction. ${ }^{19}$ However, the presence in the compound of the primary amide moiety, a well-known versatile structural element which can give rise to different synthons in the solid state, ${ }^{18,20}$ led us to search for the existence of other polymorphs of 1-MH. As described in detail below, a second polymorph of the compound could indeed be successfully identified.

\section{EXPERIMENTAL AND COMPUTATIONAL METHODS}

1-Methylhydantoin was purchased from Sigma-Aldrich (98\% purity). The matrices were prepared by codeposition of 1-MH and argon (Air Liquide, N60) onto a CsI window, mounted at the cold $(10 \mathrm{~K})$ tip of the cryostat (APD Cryogenics closedcycle helium-cooled refrigerator system with a DE-202A expander). 1-MH vapors were obtained by in situ vacuum sublimation of the compound placed in a thermoelectrically heatable furnace assembled inside the cryostat. The temperature of the sample holder (CsI window) was measured by a silicon diode temperature sensor, connected to a digital controller (LakeShore Model 331), with an accuracy of 0.1 $\mathrm{K}$. The low temperature film of the neat compound was prepared in a similar way but with the argon inlet closed. For the temperature variation spectroscopic studies performed at temperatures above room temperature the standard technique of dilution of the polycrystalline compound in a $\mathrm{KBr}$ pellet was used. The $\mathrm{KBr}$ pellet was placed in a high-precision temperature variation cell (Mettler-Toledo FP84HT), with FP90 controlling unit.

The infrared spectra were recorded, with $0.5 \mathrm{~cm}^{-1}$ resolution, using a Thermo Nicolet 6700 Fourier transform infrared (FTIR) spectrometer, equipped with a $\mathrm{Ge} / \mathrm{KBr}$ beam splitter and a deuterated triglycine sulfate (DTGS) detector. To avoid interferences from $\mathrm{H}_{2} \mathrm{O}$ and $\mathrm{CO}_{2}$, a flux of air free of water vapor and carbon dioxide continuously purged the optical path of the spectrometer. ATR infrared spectra were also collected, with $1 \mathrm{~cm}^{-1}$ spectral resolution, in a ThermoNicolet IR300 FTIR spectrometer, equipped with a Smart Orbit ATR accessory, a DTGS detector and a $\mathrm{Ge} / \mathrm{KBr}$ beam splitter.

The matrices were irradiated through an outer quartz window of the cryostat with broadband UV light produced by a $500 \mathrm{~W} \mathrm{Hg}(\mathrm{Xe})$ lamp (Newport, Oriel Instruments) set up to provide an output of $200 \mathrm{~W}$ at the sample or narrowband (fwhm $0.2 \mathrm{~cm}^{-1}$ ) UV light provided by a Spectra Physics MOPO-SL tuned at $230 \mathrm{~nm}$ (repetition rate $=10 \mathrm{~Hz}$, pulse energy $10 \mathrm{~mJ}$, duration $=10 \mathrm{~ns}$ ). The MOPO was pumped by a pulsed Quanta Ray Pro-Series Nd:YAG laser. In the broadband irradiation experiments, the $\mathrm{Hg}(\mathrm{Xe})$ lamp was fitted with a water filter $(8 \mathrm{~cm}$ long) to absorb heat, and appropriate UVcutoff filters were used to select wavelength range $(\lambda>367$, $328,295,234 \mathrm{~nm})$.

Differential scanning calorimetry (DSC) measurements were done using a Pyris-1 power compensation calorimeter from PerkinElmer, with an intracooling unit at $-25{ }^{\circ} \mathrm{C}$ (ethylene glycol-water, $1: 1 \mathrm{v} / \mathrm{v}$, cooling mixture) and a $20 \mathrm{~mL} \mathrm{~min}^{-1}$ nitrogen purge flow. Samples $(0.8-3 \mathrm{mg})$ were hermetically sealed in aluminum pans, with an empty pan used as reference. Temperature and enthalpy calibration were performed with indium (PerkinElmer, $x=99.99 \%, T_{\text {fus }}=156.60{ }^{\circ} \mathrm{C}$ ) and byphenyl (CRM LGC, $\left.T_{\text {fus }}=68.93{ }^{\circ} \mathrm{C} \pm 0.03{ }^{\circ} \mathrm{C}\right) .{ }^{21}$ In the DSC experiments, the samples were scanned from 25 to $162^{\circ} \mathrm{C}$ at a scan rate $\beta=10{ }^{\circ} \mathrm{C} \min ^{-1}$.

Polarized light thermal microscopy (PLTM) was used to obtain images of the compound within the same range of temperature used in DSC experiments. A hot stage Linkam system (model DSC600) was used, with a Leica DMRB microscope and a Sony CCD-IRIS/RGB video camera. The image analysis was performed using the Real Time Video Measurement System software from Linkam. The images were obtained by combined use of polarized light and wave compensators, using a $200 \times$ magnification.

All density functional theory (DFT) calculations were carried out using the Gaussian 09 program. ${ }^{22}$ The three-parameter B3LYP density functional, including the Becke's gradient exchange correction ${ }^{23}$ and the Lee, Yang, and Parr correlation functional, ${ }^{24}$ was used together with the $6-311++G(d, p)$ basis set. $^{25}$ The vibrational spectra of $1-\mathrm{MH}$ were calculated at the same level of theory. In order to correct the basis set limitation and anharmonicity effects, the calculated B3LYP/6-311+ $+\mathrm{G}(\mathrm{d}, \mathrm{p})$ harmonic vibrational frequencies were scaled by 0.957 , above $3400 \mathrm{~cm}^{-1}$, and by 0.980 , below $3400 \mathrm{~cm}^{-1}$. The normal coordinate analysis was performed using a locally modified version of the program BALGA, according to the methodology described by Schatschneider and Mortimer. ${ }^{26}$ The symmetry internal coordinates used in this analysis were defined as recommended by Pulay et al. ${ }^{27}$ Natural bond orbitals analysis (NBO) was performed according to Weinhold and coworkers $^{28,29}$ using NBO 3.1, as implemented in Gaussian 09. Atoms in molecules (AIM) analysis ${ }^{30}$ of the electron density of 
Table 1. B3LYP/6-311++G(d,p) Optimized Geometrical Parameters for the Minimum Energy Structure of 1-MH and Comparison with Those Obtained ${ }^{17}$ at the Same Level of Theory for the Parent Hydantoin ${ }^{a}$

\begin{tabular}{|c|c|c|c|c|c|}
\hline \multicolumn{2}{|c|}{ bond length/Å } & \multicolumn{2}{|c|}{ angle/deg } & \multicolumn{2}{|c|}{ dihedral angle/deg } \\
\hline $\mathrm{N} 1-\mathrm{C} 2$ & $1.369(-1)$ & $\mathrm{C} 2-\mathrm{N} 1-\mathrm{C} 5$ & $112.2(-11)$ & $\mathrm{C} 2-\mathrm{N} 1-\mathrm{C} 5-\mathrm{H} 10,11$ & $\pm 118.5(7)$ \\
\hline $\mathrm{N} 1-\mathrm{C} 5$ & $1.451(0)$ & $\mathrm{C} 2-\mathrm{N} 1-\mathrm{C} 6$ & $123.5^{b}(27)$ & $\mathrm{C} 6-\mathrm{N} 1-\mathrm{C} 5-\mathrm{H} 10,11$ & $\pm 61.5(-7)$ \\
\hline $\mathrm{N} 1-\mathrm{C} 6$ & $1.448-$ & $\mathrm{C} 5-\mathrm{N} 1-\mathrm{C} 6$ & $124.2^{b}(-16)$ & $\mathrm{C} 2-\mathrm{N} 1-\mathrm{C} 6-\mathrm{H} 12,14$ & $\pm 119.4-$ \\
\hline $\mathrm{C} 2-\mathrm{N} 3$ & $1.414(1)$ & $\mathrm{N} 1-\mathrm{C} 2-\mathrm{N} 3$ & $105.9(6)$ & $\mathrm{C} 5-\mathrm{N} 1-\mathrm{C} 6-\mathrm{H} 12,14$ & $\pm 60.6-$ \\
\hline $\mathrm{C} 2=\mathrm{O} 7$ & $1.210(3)$ & $\mathrm{N} 1-\mathrm{C} 2=\mathrm{O} 7$ & $128.6(-2)$ & $\mathrm{N} 3-\mathrm{C} 4-\mathrm{C} 5-\mathrm{H} 10,11$ & \pm 120.5 \\
\hline $\mathrm{N} 3-\mathrm{C} 4$ & $1.376(-2)$ & $\mathrm{N} 3-\mathrm{C} 2=\mathrm{O} 7$ & $125.5(-4)$ & $\mathrm{O} 9=\mathrm{C} 4-\mathrm{C} 5-\mathrm{H} 10,11$ & $\pm 59.5(-1)$ \\
\hline $\mathrm{N} 3-\mathrm{H} 8$ & $1.009(0)$ & $\mathrm{C} 2-\mathrm{N} 3-\mathrm{C} 4$ & $113.5(-1)$ & & \\
\hline $\mathrm{C} 4-\mathrm{C} 5$ & $1.531(-3)$ & $\mathrm{C} 2-\mathrm{N} 3-\mathrm{H} 8$ & $122.0(0)$ & & \\
\hline $\mathrm{C} 4=\mathrm{O} 9$ & $1.207(1)$ & $\mathrm{C} 4-\mathrm{N} 3-\mathrm{H} 8$ & $124.5(2)$ & & \\
\hline $\mathrm{C} 5-\mathrm{H} 10,11$ & $1.096(2)$ & $\mathrm{N} 3-\mathrm{C} 4-\mathrm{C} 5$ & $105.0(-3)$ & & \\
\hline C6-H12,14 & $1.095-$ & $\mathrm{N} 3-\mathrm{C} 4=\mathrm{O} 9$ & $127.7(6)$ & & \\
\hline C6-H13 & $1.089-$ & $\mathrm{C} 5-\mathrm{C} 4=\mathrm{O} 9$ & $127.3(2)$ & & \\
\hline & & $\mathrm{N} 1-\mathrm{C} 5-\mathrm{C} 4$ & $103.3(9)$ & & \\
\hline & & $\mathrm{N} 1-\mathrm{C} 5-\mathrm{H} 10,11$ & $112.7(-5)$ & & \\
\hline & & $\mathrm{C} 4-\mathrm{C} 5-\mathrm{H} 10,11$ & $109.8(3)$ & & \\
\hline & & $\mathrm{H} 10-\mathrm{C} 5-\mathrm{H} 11$ & $108.4(-4)$ & & \\
\hline & & $\mathrm{N} 1-\mathrm{C} 6-\mathrm{H} 12,14$ & $111.0-$ & & \\
\hline & & $\mathrm{N} 1-\mathrm{C} 6-\mathrm{H} 13$ & $108.0-$ & & \\
\hline & & $\mathrm{H} 12-\mathrm{C} 6-\mathrm{H} 14$ & $108.9-$ & & \\
\hline & & $\mathrm{H} 13-\mathrm{C} 6-\mathrm{H} 12,14$ & $109.0-$ & & \\
\hline
\end{tabular}

${ }^{a}$ See atom numbering in Scheme 1 . Numbers in parentheses correspond to the variation (in units of the last digit) of the structural parameters in going from hydantoin to $1-\mathrm{MH} .{ }^{b}$ In hydantoin, $\mathrm{C} 2-\mathrm{N} 1-\mathrm{H} 6$ and $\mathrm{C} 5-\mathrm{N} 1-\mathrm{H} 6$.

1-MH was performed with the MultiWFN (version 3.2) program package. ${ }^{31}$

\section{RESULTS AND DISCUSSION}

Structure of the 1-MH Molecule. The calculated geometrical parameters for ground state minimum energy conformation of 1-MH are shown in Table 1, where they are compared with those obtained at the same level of theory for the parent hydantoin. According to the performed calculations, the 1-MH molecule has $C_{s}$ symmetry, with a planar ring and the methyl substituent oriented so that the hydrogen atom located in the ring plane is oriented toward O7 (see Scheme 1). This methyl group orientation ensures stabilization of the molecule through the intramolecular electrostatic interaction resulting from the antiparallel alignment of the dipoles associated with the $\mathrm{C} 6-\mathrm{H} 13$ and $\mathrm{C} 2=\mathrm{O} 7$ bonds (see Scheme 1).

The most interesting results regarding the geometry of $1-\mathrm{MH}$ are the following: $(a)$ the bond length of the carbonyl group connected to two nitrogen atoms $(\mathrm{C} 2=\mathrm{O} 7 ; 1.210 \AA)$ is longer than that of the carbonyl group connected to a single nitrogen atom $(\mathrm{C} 4=\mathrm{O} 9 ; 1.207 \AA)$, in consonance with the expected larger total $\pi$ electron delocalization from the nitrogen atoms to $\mathrm{O} 7$ atom, compared to O9; $(b)$ the ring $\mathrm{C}_{s p 2}-\mathrm{N}$ bond lengths follow the order $\mathrm{C} 2-\mathrm{N} 1<\mathrm{C} 4-\mathrm{N} 3<\mathrm{C} 2-\mathrm{N} 3(1.369,1.376$, $1.414 \AA$, respectively), pointing to a maximum $\mathrm{N}$-to-O electron delocalization in the fragment $\mathrm{N1C2O}$, i.e., when the nitrogen atom has only an oxygen atom as acceptor, while the minimum $\mathrm{N}$-to-O electron donation occurs in the $\mathrm{N} 3 \mathrm{C} 2 \mathrm{O} 7$ fragment because N3 has to donate electronic charge to both $\mathrm{O} 7$ and 09 and, since $\mathrm{O} 7$ has another donor (N1), N3 donates preferentially to O9; (c) the two $\mathrm{C}_{s p 3}-\mathrm{N}$ bond lengths (exocyclic $\mathrm{C} 6-\mathrm{N} 1$ and ring $\mathrm{C} 5-\mathrm{N} 1$ ) do not differ very much (1.448 and $1.151 \AA$, respectively), and the C4-C5 bond length $(1.531 \AA)$ is somewhat longer than the typical $\mathrm{C}_{s p 3}-\mathrm{C}_{s p 2}$ length $(\sim 1.50 \AA),{ }^{32}$ indicating that in the $\mathrm{C}-\mathrm{CH}_{2}-\mathrm{N}-\mathrm{CH}_{3}$ fragment the electron delocalization is minimal; $(d)$ the internal angles of the ring with a nitrogen atom in the apex $(\mathrm{C} 4-\mathrm{N} 3-\mathrm{C} 2$ and $\mathrm{C} 2-\mathrm{N} 1-\mathrm{C} 5)$ are much larger $\left(112-114^{\circ}\right)$ than those with carbon atoms in the apex $(\mathrm{N} 1-\mathrm{C} 2-\mathrm{N} 3, \mathrm{~N} 3-\mathrm{C} 4-\mathrm{C} 5$ and N1$\left.\mathrm{C} 5-\mathrm{C} 4 ; \sim 103-106^{\circ}\right)$, suggesting quite different $s-p$ composition of the hybrid orbitals of the $\mathrm{N}$ and $\mathrm{C}$ atoms used to make the ring bonds (we shall turn to this point later); (e) the geometry of $1-\mathrm{MH}$ is very similar to that of the parent hydantoin molecule (see Table 1), indicating that the electronic effects due to the methyl substituent are not much relevant; on the other hand, as seen in Table 1 , the $\mathrm{C} 2-\mathrm{N} 1-\mathrm{X} 6$ and $\mathrm{C} 5-$ $\mathrm{N} 1-\mathrm{X} 6$ angles are substantially different in hydantoin $(\mathrm{X}=\mathrm{H})$ and 1- $\mathrm{MH}\left(\mathrm{X}=\mathrm{CH}_{3}\right)$, in consequence of steric effects resulting from the $\mathrm{H}$-by-methyl substitution; since the in-plane hydrogen atom of the methyl group in $1-\mathrm{MH}$ is pointing to $\mathrm{C} 2$, the $\mathrm{C} 2-$ $\mathrm{N} 1-\mathrm{X} 6$ angle increases by $2.7^{\circ}$ in going from hydantoin to 1 $\mathrm{MH}$ in order to reduce hindrance between that hydrogen atom and $\mathrm{O} 7$, whereas the opposite angle $(\mathrm{C} 5-\mathrm{N} 1-\mathrm{X} 6)$ reduces by $1.6^{\circ}$ (the $\mathrm{C} 2-\mathrm{N} 1-\mathrm{C} 5$ angle undergoes a smaller reduction of $\left.1.1^{\circ}\right)$. As described in detail below, most of the noted characteristic geometrical attributes of the 1-MH molecule can be correlated with electronic features.

Charge Density Analyses of the 1-MH Molecule (NBO and AIM). Analyses of the charge distribution in the molecule of $1-\mathrm{MH}$ and of the topological properties of the electron density and gradient of electron density allowed us to understand some of the fundamental structural characteristics of the molecule and extract conclusions relevant for its chemical reactivity.

NBO Analysis. The performed NBO analysis was particularly successful to shed light on the specific characteristics of the $\sigma$ and $\pi$ electronic systems of the molecule.

Table 2 shows the total, $\sigma$ and $\pi$ NBO atomic charges for 1$\mathrm{MH}$. As shown in the table, the total charges of the nitrogen atoms (N1 and N3) are negative, as we could anticipate, 
Table 2. Natural Bond Orbital (NBO) Atomic Charges (in Units of Electron; $e=1.60217646 \times 10^{-19} \mathrm{C}$ ) for $1-\mathrm{MH}$, Obtained from the DFT(B3LYP $) / 6-311++G(d, p)$ Calculations $^{a}$

\begin{tabular}{lccc} 
& \multicolumn{3}{c}{ NBO charge } \\
\cline { 2 - 4 } atom & total & $\sigma$ & $\pi$ \\
N1 & -0.516 & -0.805 & 0.289 \\
C2 & 0.819 & 0.645 & 0.174 \\
N3 & -0.654 & -0.991 & 0.336 \\
C4 & 0.683 & 0.466 & 0.216 \\
C5 & -0.247 & -0.030 & -0.217 \\
C6 & -0.355 & -0.156 & -0.199 \\
O7 & -0.621 & -0.091 & -0.530 \\
H8 & 0.421 & - & - \\
O9 & -0.578 & -0.121 & -0.457 \\
H10,11 & 0.218 & - & - \\
H12,14 & 0.190 & - & - \\
H13 & 0.233 & - & - \\
${ }^{a}$ See Scheme1 for atom numbering. & & \\
\hline
\end{tabular}

because the nitrogen atoms are more electronegative than the carbon atoms to which they are attached. Similarly, the C2 and $\mathrm{C} 4$ carbon atoms, which are connected to more electronegative oxygen and nitrogen atoms, have positive total charges, while C5 and C6 are bonded to hydrogen atoms and, therefore, show negative total charges. As C6 is bonded to 3 hydrogen atoms, this carbon atom is more negative than $\mathrm{C} 5$, which is bonded only to two hydrogen atoms. The oxygen atoms (O7 and O9) are the most electronegative atoms in the molecule and show total charges that are significantly negative.

The analysis of the charge distribution in 1-MH based on the total charges is quite simplistic. Considerably more interesting details of the electron distribution in the molecule can be revealed by the analysis of the NBO charges partition in terms of $\sigma$ and $\pi$ systems. From this analysis, it can notice that, despite of having a negative total charge, the nitrogen atoms show a positive $\pi$ charge, in agreement with the mesomeric structures depicted in Scheme 2. Note also that the N3 atom has a $\pi$ charge that is more positive than that of $\mathrm{N} 1$, in agreement with the fact that $\mathrm{N} 3$ shows a positive charge in

Scheme 2. (I) Dominant Canonic Form of 1-

Methylhydantoin; (II, III, and IV) Mesomeric Structures Assuming Delocalization of $\pi$ Electrons in the Molecule's NCO Moieties

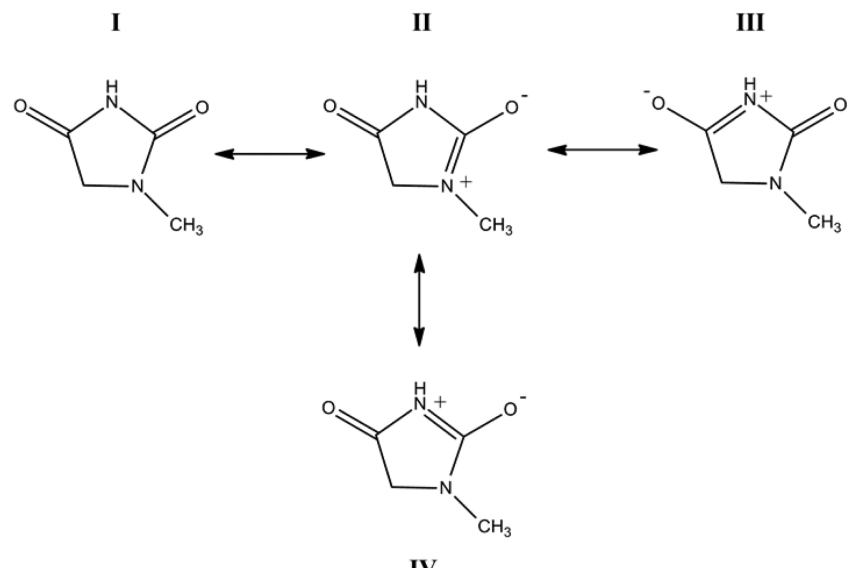

mesomeric structures III and IV, whereas N1 shows only a positive charge in mesomeric structure II. A similar reasoning can be applied to understand the relative values of the $\pi$ charges of the two oxygen atoms. Since O7 shows a negative charge in two mesomeric structures (II and IV), while O9 is negatively charged in only one mesomeric structure (III), O7 has a more negative $\pi$ charge than $\mathrm{O}$.

It is also interesting to notice that the $\sigma$ charges of the two oxygen atoms are considerably less negative than the corresponding $\pi$ charges, and have opposite relative values (namely, O9 $\sigma$ charge is more negative than $07 \sigma$ charge). This shows that, compared to $\mathrm{C} 4=\mathrm{O} 9$, the higher $\mathrm{C} 2=\mathrm{O} 7 \pi$ bond polarization toward oxygen leads to reduce the trend for the associated $\sigma$ bond to be polarized in the same direction. The $\mathrm{O} 7$ atom is, nevertheless, the most negatively charged oxygen atom, in result of its highly polarized $\pi$ bond through mesomerism. Indeed, these results are in perfect agreement with the structural results (specifically the relative $\mathrm{C} 2=\mathrm{O} 7$ and $\mathrm{C} 4=09$ bond lengths) discussed in the previous section, which indicate a larger $\pi$ electron delocalization from the nitrogen atoms to O7, compared to O9.

The relative values of the $\pi$ charges on the nitrogen atoms are also consistent with the relative values of the ring $\mathrm{C}_{s p 2}-\mathrm{N}$ bond lengths that, as discussed above, point to a maximum $\mathrm{N}$ to-O electron delocalization in the fragment $\mathrm{N} 1 \mathrm{C} 2 \mathrm{O} 7$. In fact, the positive $\pi$ charge of $\mathrm{N} 1(+0.289 e$; resulting essentially from the $\pi$ delocalization to O7, as shown in Scheme 2) is considerably larger than half of the positive charge of $\mathrm{N} 3$ $(+0.168 e)$, which donates $\pi$ electron charge to both $\mathrm{O} 7$ and O9.

In the case of $\mathrm{C} 2$ and $\mathrm{C} 4$ atoms, it is noted that both $\pi$ and $\sigma$ charges are positive, being the $\sigma$ charge contribution the prevalent one, while the reverse situation occurs for C5 and C6, which show negative $\sigma$ and $\pi$ charges, with the prevalent contribution to the total charge being due to the $\pi$ system.

The relative importance of the mesomerism within the different NCO fragments of the 1-MH molecule (as well as other relevant intramolecular interactions) can also be evaluated by taking into account the most relevant NBO interactions. These interactions are listed in Table 3 and graphically represented in Figure S1 (Supporting Information). Orbital interaction energies, $E(2)$, between filled and empty NBOs (including non-Lewis extra valence Rydberg orbitals) are obtained from the second-order perturbation approach,

Table 3. Stabilization Energies for Selected NBO Pairs, As Given by Second Order Perturbation Theory Analysis of the Fock Matrix in the NBO Basis, for 1-MH, Obtained from the B3LYP/6-311++G(d,p) Calculations ${ }^{a}$

$\begin{array}{cccc}\text { pair name } & \text { donor NBO } & \text { acceptor NBO } & E(2) \text { energy }\left(\mathrm{kJ} \mathrm{mol}^{-1}\right) \\ \text { A } & \text { LP (N1) } & \pi^{*}(\mathrm{C} 2-\mathrm{O} 7) & 64.23 \\ \text { B } & \text { LP (N3) } & \pi^{*}(\mathrm{C} 2-\mathrm{O} 7) & 47.23 \\ \text { C } & \text { LP (N3) } & \pi^{*}(\mathrm{C} 4-\mathrm{O} 9) & 55.70 \\ \text { D } & \text { LP2 (O7) } & \sigma^{*}(\mathrm{~N} 1-\mathrm{C} 2) & 24.58 \\ \text { E } & \text { LP2 (O7) } & \sigma^{*}(\mathrm{C} 2-\mathrm{N} 3) & 28.43 \\ \text { F } & \text { LP2 (O9) } & \sigma^{*}(\mathrm{~N} 3-\mathrm{C} 4) & 27.05 \\ \text { G } & \text { LP2 (O9) } & \sigma^{*}(\mathrm{C} 4-\mathrm{C} 5) & 22.11 \\ \text { H } & \text { LP1 (O7) } & \mathrm{RY}^{*}(\mathrm{C} 2) & 18.01 \\ \text { I } & \text { LP1 (O9) } & \mathrm{RY}^{*}(\mathrm{C} 4) & 17.89\end{array}$

${ }^{a}$ See atom numbering in Scheme 1. LP, lone electron pair orbital. Ry, Rydberg type orbital. 
Table 4. B3LYP/6-311++G(d,p) Calculated Bond Lengths $(r / \AA ̊)$ and Bond Angles $(\alpha / \mathrm{deg})$ of the 1-MH Ring, and Molecular Charge Density at the Bond Critical Points $\left(\rho_{(\mathrm{BCP})} / e\right)$ and Bond-Path Angles $\left(\alpha_{(\mathrm{BP})} / \mathrm{deg}\right)$ Resulting from the AIM Analysis ${ }^{a}$

$\begin{array}{lcccccc} & r & \rho(\mathrm{BCP}) & & \alpha & \alpha(\mathrm{BP}) & \alpha(\mathrm{BP})-\alpha \\ \mathrm{N} 1-\mathrm{C} 2 & 1.369 & 0.320 & \mathrm{C} 2-\mathrm{N} 1-\mathrm{C} 5 & 112.2 & 112.4 & 0.2 \\ \text { C2-N3 } & 1.414 & 0.292 & \text { N1-C5-C4 } & 103.3 & 103.3 & 0.0 \\ \text { N3-C4 } & 1.376 & 0.311 & \text { C5-C4-N3 } & 105.0 & 105.4 & 0.4 \\ \text { C4-C5 } & 1.531 & 0.251 & \text { C4-N3-C2 } & 113.5 & 113.9 & 0.4 \\ \text { C5-N1 } & 1.451 & 0.266 & \text { N3-C2-N1 } & 105.9 & 106.1 & 0.2\end{array}$

${ }^{a}$ In the AIM analysis, the B3LYP/6-311++G(d,p) wave function was used.

$$
E(2)=\Delta E_{i j}=q_{i} \frac{F_{i j}^{2}}{\varepsilon_{j}-\varepsilon_{i}}
$$

where $F_{i j}^{2}$ is the Fock matrix element between $i$ and $j \mathrm{NBO}$ orbitals, $\varepsilon_{j}$ and $\varepsilon_{i}$ are the energies of the acceptor and donor NBOs, and $q_{i}$ is the occupancy of the donor orbital.

As it is shown in Table 3 , the most important NBO interactions $(\mathrm{A}, \mathrm{B}, \mathrm{C})$ involve electronic charge transfer from the nitrogen atoms to carbonyl bonds and can be directly related with the mesomeric structures II, III, and IV in Scheme 2. In case of $\mathrm{N} 1$, the electronic charge transfer is exclusive to the $\pi^{*}(\mathrm{C} 2-\mathrm{O} 7)$ antibonding orbital, while $\mathrm{N} 3$ donates electronic charge to both $\pi^{*}(\mathrm{C} 2-\mathrm{O} 7)$ and $\pi^{*}(\mathrm{C} 4-\mathrm{O} 9)$ antibonding orbitals. As expected, due to competition between these two interactions involving $\mathrm{N} 3$, the $E(2)$ relative interaction energies for $\mathrm{LP}(\mathrm{N} 3) \rightarrow \pi^{*}(\mathrm{C} 2-\mathrm{O} 7)[47.23 \mathrm{~kJ}$ $\left.\mathrm{mol}^{-1}\right]$ and $\mathrm{LP}(\mathrm{N} 3) \rightarrow \pi^{*}(\mathrm{C} 4-\mathrm{O} 9)\left[55.70 \mathrm{~kJ} \mathrm{~mol}^{-1}\right]$ orbital interactions are smaller than that corresponding to the $\mathrm{LP}(\mathrm{N} 1)$ $\rightarrow \pi^{*}(\mathrm{C} 2-\mathrm{O} 7)\left[64.23 \mathrm{~kJ} \mathrm{~mol}^{-1}\right]$ orbital interaction. On the other hand, because the $\pi^{*}(\mathrm{C} 2-\mathrm{O} 7)$ antibonding orbital receives electronic charge from both nitrogen atoms ( $\mathrm{N} 1$ and $\mathrm{N} 3)$, the $\mathrm{LP}(\mathrm{N} 3) \rightarrow \pi^{*}(\mathrm{C} 2-\mathrm{O} 7)$ interaction energy is smaller than the $\mathrm{LP}(\mathrm{N} 3) \rightarrow \pi^{*}(\mathrm{C} 4-\mathrm{O} 9)$ interaction energy. It is remarkable, however, that as a whole the electronic charge transferred from N1 and N3 atoms to $\pi^{*}(\mathrm{C} 2-\mathrm{O} 7)$ antibonding orbital is considerably larger than the one that results from the single interaction associated with the $\pi^{*}(\mathrm{C} 4-\mathrm{O} 9)$ antibonding orbital (compare the total interaction energy values $\mathrm{A}+\mathrm{B}$ with $\mathrm{C}$, in Table 3), also in agreement with the more negative $\pi$ charge of $\mathrm{O} 7(-0.530 \mathrm{e})$ when compared with that of $\mathrm{O} 9$ $(-0.457 e)$. All these results are also in agreement with the conclusions extracted from the structural data presented in the previous section, specifically the relative lengths of the $\mathrm{C}=\mathrm{O}$ and $\mathrm{C}_{s p 2}-\mathrm{N}$ bonds $(\mathrm{C} 2=\mathrm{O} 7>\mathrm{C} 4=\mathrm{O} 9 ; \mathrm{C} 2-\mathrm{N} 1<\mathrm{C} 4-\mathrm{N} 3<$ $\mathrm{C} 2-\mathrm{N} 3$ ).

The remaining main NBO interactions (D-I in Table 3) are correlated with other types of intramolecular interactions:

(i) The NBO orbital interactions designated as D, E, F, and $\mathrm{G}$ occur between the nonbonded electron pair (LP2; $\sigma$ ) of O7 and $\mathrm{O} 9$ oxygen atoms and the antibonding $\sigma^{*}$ orbitals of the neighbor $\mathrm{C}-\mathrm{N}$ bonds. This kind of interaction represent the well-known electron back-donation effect involving carbonyl oxygen atoms ${ }^{33-36}$ that explains, for example, the unusually short $\mathrm{C}-\mathrm{H}$ bond length in aldehydes and derivatives of formic acid, and that reflects also in the unusually low $\nu(\mathrm{C}-\mathrm{H})$ stretching vibrational frequency in these types of molecules. In $1-\mathrm{MH}$, these interactions also contribute to determine the relative lengths of the $\mathrm{C} 2-\mathrm{N} 3, \mathrm{C} 4-\mathrm{N} 3$, and $\mathrm{C} 2-\mathrm{N} 1$ bonds (1.414, 1.376, and $1.369 \AA$, respectively): the stronger the backdonation from the donor carbonyl lone pair to the acceptor antibonding orbital of a given $\mathrm{C}_{s p 2}-\mathrm{N}$ ring-bond, the longer the bond. (ii) NBO orbital interactions designated $\mathrm{H}$ and $\mathrm{I}$ in Table 3 describe the electronic charge transfer from the second nonbonded electron pair (LP1; $\sigma$ ) of the oxygen atoms to one Rydberg orbital of the corresponding carbonyl carbon atom. These interactions are associated with effects related to the carbonyl bond polarization, working specifically as moderators of the $\sigma$ polarization of the carbonyl bonds to compensate the effects of the increased $\pi$ polarization due to interactions A, B, and C (see Table 3).

The analysis of the $s-p$ composition of the hybrid NBO's of the ring nitrogen and carbon atoms allows to explain why the internal angles of the ring are considerably larger when a nitrogen atom is in the angle apex $(\mathrm{C} 4-\mathrm{N} 3-\mathrm{C} 2$ and $\mathrm{C} 2-\mathrm{N} 1-$ $\left.\mathrm{C} 5 ; 112-114^{\circ}\right)$ than when a carbon atom is the apex (N1$\mathrm{C} 2-\mathrm{N} 3, \mathrm{~N} 3-\mathrm{C} 4-\mathrm{C} 5$, and $\mathrm{N} 1-\mathrm{C} 5-\mathrm{C} 4 ; \sim 103-106^{\circ}$ ). As mentioned before, such observation suggests different $s-p$ composition of the hybrid orbitals of the $\mathrm{N}$ and $\mathrm{C}$ atoms used to make the ring bonds. A smaller $\mathrm{p}$ contribution to the hybrid orbital correlates with larger angles, ${ }^{37,38}$ so that the average $p$ contribution to the hybrid orbitals used to establish the ring bonding NBO's by the nitrogen atoms ( $\mathrm{N} 1$ and $\mathrm{N} 3$ ) shall be smaller than that used by the carbon atoms (C2, C4 and C5). Accordingly, the hybridization of the orbitals used by $\mathrm{N} 1$ and $\mathrm{N} 3$ to form the ring NBOs were calculated to be $\mathrm{sp}^{2.17}$ (N1C5), $\mathrm{sp}^{1.96}(\mathrm{~N} 1-\mathrm{C} 2), \mathrm{sp}^{1.80}(\mathrm{~N} 3-\mathrm{C} 4)$, and $\mathrm{sp}^{1.99}(\mathrm{~N} 3-\mathrm{C} 2)$, as expected exhibiting average smaller $\mathrm{p}$ contributions per atom than those used by the carbon atoms, $\mathrm{sp}^{2.01}(\mathrm{C} 2-\mathrm{N} 1), \mathrm{sp}^{2.30}$ (C2-N3), $\mathrm{sp}^{2.28}(\mathbf{C} 4-\mathrm{N} 3), \mathrm{sp}^{1.94}$ (C4-C5), $\mathrm{sp}^{3.26}$ (C5-N1), and $\mathrm{sp}^{2.87}(\mathbf{C 5}-\mathrm{C} 4)$.

AIM Analysis. As it will be described in detail later in this article, 1-MH may undergo fragmentation reactions through ring cleavage. The estimation of the relative strengths of the different bonds of the molecule is then relevant for the understanding of such processes. A simple and elegant way to perform this estimation is to use the AIM theory approach ${ }^{30}$ and evaluate the value of the charge density at the bond critical points of the molecule, then correlating these values with the bond strengths. ${ }^{30,39-43}$ Useful information regarding the stability of the different ring bonds can also be extracted from the differences between the bond-path-angles and the geometrical angles, which are a measure of the ring strain. ${ }^{30,37}$ The relevant data is presented in Table 4. Figure 1 shows the contour map of the molecular charge density $(\rho)$ in the molecular plane of $1-\mathrm{MH}$, and the trajectories of the corresponding gradients; the bond critical points, correspond to saddle points in $\rho$ and, according to the AIM theory, ${ }^{30}$ the presence of a bond between two atoms in a molecule leads to the appearance of such a critical point in the region between these two atoms.

From Table 4, it can be seen that a direct correlation between the value of the charge density at the bond critical points of the five bonds of the 1-MH ring and the 


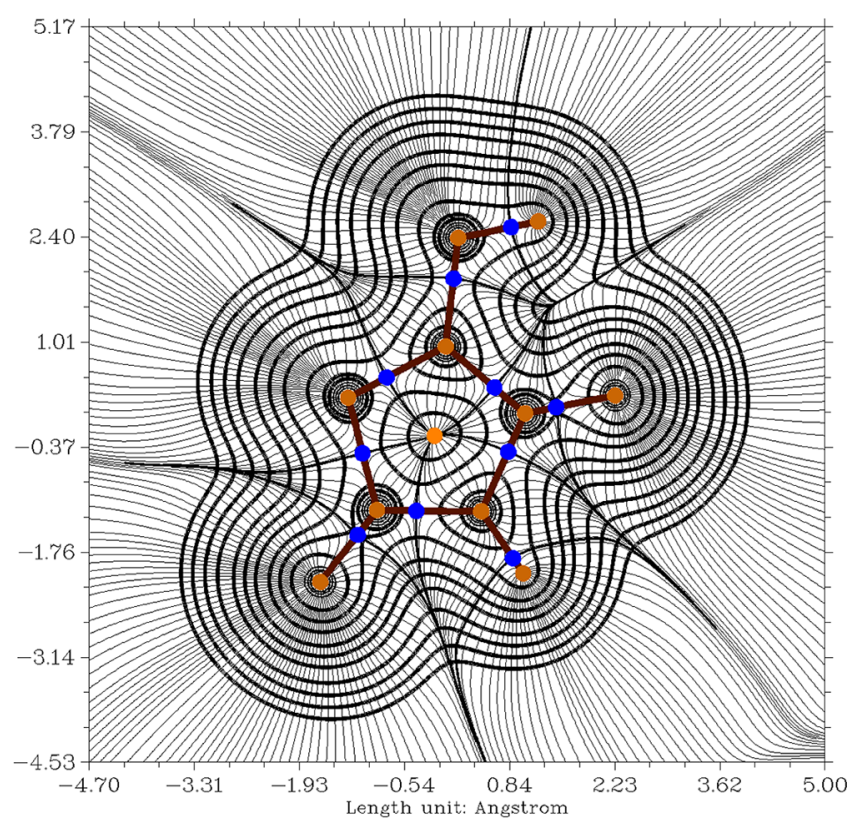

Figure 1. Contour map of the molecular charge density $(\rho)$ in the molecular plane of $1-\mathrm{MH}$, and the trajectories of the corresponding gradients. Atoms are indicated by the brown circles; the points marked with the blue and orange circles correspond to 1st and 2nd order saddle points in $\rho$ (of rank and signature $3,-1$ and $3,+1$, respectively, where the first number is the number of nonzero curvatures of $\rho$ at the critical point and the second is the algebraic sum of the signs of the curvatures) and are named bond critical points and ring critical points, as the presence of a bond between two atoms or a ring in a molecule leads to the appearance of such critical points in $\rho .^{29}$ The two unique gradient paths which originate at infinity or at a ring critical point and terminate at a bond critical point define the boundary between a pair of bonded atoms, in the considered plane. Contour values in this figure are $210^{n}, 4 \times 10^{n}$ and $8 \times 10^{n}$, where $n$ starts at -3 and increases in steps of unity.
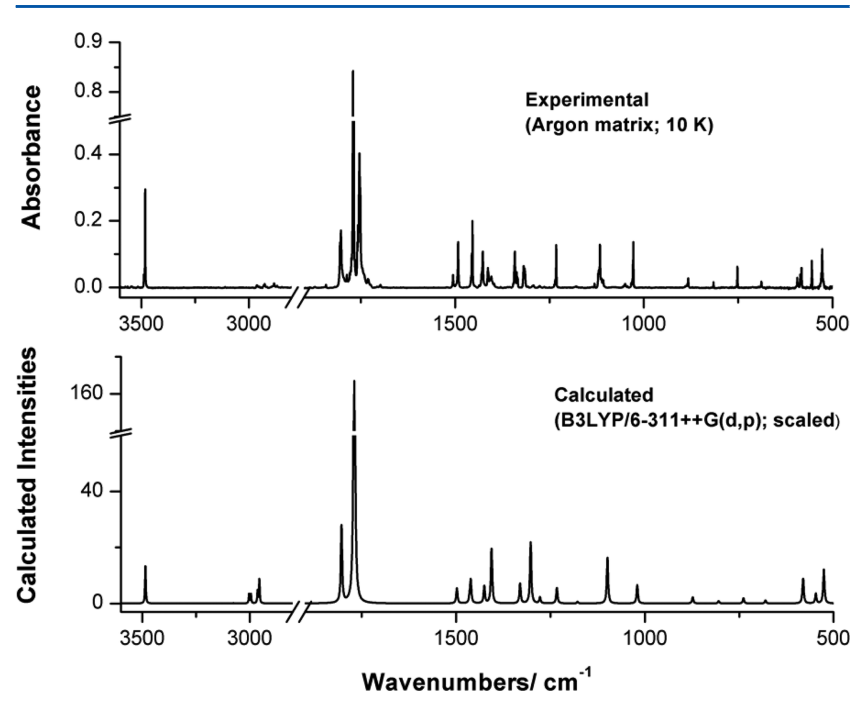

Figure 2. Experimental infrared spectrum of monomeric 1-MH isolated in an argon matrix at $10 \mathrm{~K}(t o p)$ and simulated spectrum of 1$\mathrm{MH}$ monomer using Lorenztian functions centered at the scaled B3LYP/6-311++G $(\mathrm{d}, \mathrm{p})$ calculated wavenumbers (bottom). Note that the calculated intensities correspond, in the simulated spectrum, to the area below the Lorentzian functions, not to peak intensities.

corresponding bond lengths is observed, the shorter the bond, the greater the charge density at the associated bond critical point. The structural results are then in agreement with the analysis of the electron charge density. The strongest bonds are the $\mathrm{N} 1-\mathrm{C} 2$ and $\mathrm{N} 3-\mathrm{C} 4$ bonds, while the weakest one is the C4-C5 bond. This latter can then be expected to be the one more prone to be cleaved upon fragmentation of 1-MH.

In Table 4 it can also be seen that the differences between the bond-path-angles $\left(\alpha_{(\mathrm{BP})}\right)$ and the geometrical angles $(\alpha)$ are very small, which indicates a reduced ring strain. The sum of the differences, $\sum\left(\alpha_{(\mathrm{BP})}-\alpha\right)$, amount to only $1.2^{\circ}$. Nevertheless, these results indicate that the most strained fragment in the molecule corresponds to the C5C4N3C2 moiety (with $\sim 67 \%$ of the total ring strain), and that, in consequence, elimination of isocyanic acid (specifically the fragment $\mathrm{H} 8 \mathrm{~N} 3 \mathrm{C} 4 \mathrm{O} 9$ ) appears as a favored fragmentation process in 1-MH.

IR Spectrum of Matrix-Isolated 1-MH. The matrix isolated infrared spectrum of $1-\mathrm{MH}$ in argon matrix (at 10 $\mathrm{K})$ is presented, together with the B3LYP/6-311++G(d,p) calculated spectrum of the compound, in Figure 2. The proposed band assignments, based on the calculated potential energy distributions (PED) resulting from the performed normal coordinate analysis, are provided in Table 5. The definitions of the internal symmetry coordinates used in the PED analysis are provided in Table S1 (Supporting Information).

The good overall agreement between the experimental and calculated spectra assures a reliable assignment of the experimental IR bands. In the following discussion only the structurally most relevant features of the spectrum of $1-\mathrm{MH}$ will be considered.

The most intense feature in the infrared spectra of 1-MH is due to the antisymmetric carbonyl stretching vibration $(\nu(\mathrm{C}=$ $\mathrm{O})_{\text {as }}$ ), and observed as a matrix site-split band with maxima at $1771,1768 \mathrm{~cm}^{-1}$. The relatively intense band observed at $\sim 1753 \mathrm{~cm}^{-1}$ can be explained in terms of the Fermi resonance interaction between the first overtone of ring skeletal vibration which fundamental is observed at $884 / 883 \mathrm{~cm}^{-1}$ and the antisymmetric carbonyl stretching vibration. A similar Fermi resonance interaction was found to take place in the case of the parent hydantoin. ${ }^{17}$ The relatively intense band associated with the symmetric carbonyl stretching vibration (calculated at 1804 $\mathrm{cm}^{-1}$ ) is observed as a site-split doublet at 1803 and $1805 \mathrm{~cm}^{-1}$.

The bands due to the three vibrations of the $\mathrm{NH}$ group are observed as site-split features at 3488/3482 (stretching, $\nu(\mathrm{NH})), \sim 1340$ (in-plane bending, $\delta(\mathrm{NH})$, exhibiting four components), and $530 / 527 \mathrm{~cm}^{-1}$ (out-of-plane rocking, $\gamma(\mathrm{NH}))$. These are the bands which can be anticipated to undergo larger changes with the sampling conditions, in particular in going from the matrix isolated monomer to the condensed phases. As described in detail below, in the spectra of the neat compound in solid state (either amorphous or crystalline phases) these bands shift considerably to lower and higher frequencies, respectively in case of the stretching and bending modes. These characteristic frequency shifts upon hydrogen bond formation in the solid states, as well as the strong dependence with temperature of the bands position, intensity and profile, and good reproduction of the spectra for the isolated monomer by the theoretical calculations (calculated values: 3486,1331 , and $526 \mathrm{~cm}^{-1}$, for stretching, in-plane bending and rocking modes, respectively), allowed for a secure assignment of the three vibrations originated in the $\mathrm{NH}$ group.

As is usually the case for matrix-isolated molecules, the bands in the $\mathrm{CH}$ stretching region appear with a comparatively 
Table 5. Infrared Spectrum of Monomeric 1-MH in Argon Matrix (10 K) and DFT(B3LYP)/6-311G++(d,p) Calculated Infrared Spectrum and Potential Energy Distributions (PED) ${ }^{a}$

\begin{tabular}{|c|c|c|c|}
\hline \multirow{2}{*}{$\begin{array}{l}\text { Experimental } \\
\text { (Ar matrix; } 10 \mathrm{~K}) \\
\text { Freq }^{b}\end{array}$} & \multicolumn{3}{|c|}{ Calculated } \\
\hline & Freq $^{b}$ & $\mathrm{I}_{\mathbb{R}}{ }^{c}$ & Symmetry and $\mathrm{PED}^{d}(\%)$ \\
\hline $3488 / 3482$ & 3486 & 85 & {$\left[\mathrm{~A}^{\prime}\right] \mathrm{v}(\mathrm{NH})(100)$} \\
\hline n.obs. & 3076 & 1 & {$\left[\mathrm{~A}^{\prime}\right] \mathrm{v}\left(\mathrm{CH}_{3}\right)_{\mathrm{as}}^{\prime}(91)$} \\
\hline $2962 / 2960$ & 3004 & 21 & {$\left[\mathrm{~A}^{\prime \prime}\right] \vee\left(\mathrm{CH}_{3}\right)_{\mathrm{as}}^{\prime \prime}(93)$} \\
\hline 2951 & 2995 & 21 & {$\left[\mathrm{~A}^{\prime \prime}\right] v\left(\mathrm{CH}_{2}\right)_{\mathrm{a}}(93)$} \\
\hline 2930 & 2964 & 28 & {$\left[\mathrm{~A}^{\prime}\right] \mathrm{v}\left(\mathrm{CH}_{2}\right)_{\mathrm{s}}(95)$} \\
\hline $2927 / 2883^{e}$ & 2956 & 55 & {$\left[\mathrm{~A}^{\prime}\right] \mathrm{v}\left(\mathrm{CH}_{3}\right)_{\mathrm{s}}(87)$} \\
\hline $1805 / 1803$ & 1804 & 174 & {$\left[\mathrm{~A}^{\prime}\right] \mathrm{v}(\mathrm{C}=\mathrm{O})_{\mathrm{s}}(82)$} \\
\hline $1771 / 1768 / \sim 1753$ & 1770 & 1053 & {$\left[\mathrm{~A}^{\prime}\right] \mathrm{v}(\mathrm{C}=\mathrm{O})_{\mathrm{as}}(76)+\mathrm{v}_{2}($ ring $)(12)$} \\
\hline $1505 / 1492$ & 1498 & 34 & {$\left[\mathrm{~A}^{\prime}\right] \delta\left(\mathrm{CH}_{3}\right)_{\mathrm{as}}{ }^{\prime}(98)+\delta\left(\mathrm{CH}_{2}\right)(12)+\gamma\left(\mathrm{CH}_{3}\right)^{\prime}(12)$} \\
\hline $1457 / 1455$ & 1464 & 12 & {$\left[\mathrm{~A}^{\prime \prime}\right] \delta\left(\mathrm{CH}_{3}\right)_{\mathrm{as}}{ }^{\prime \prime}(92)$} \\
\hline $1456 / 1454$ & 1461 & 52 & {$\left[\mathrm{~A}^{\prime}\right] \delta\left(\mathrm{CH}_{2}\right)(67)+\delta\left(\mathrm{CH}_{3}\right)_{\mathrm{as}}^{\prime}(25)$} \\
\hline $1430 / 1427$ & 1426 & 39 & {$\left[\mathrm{~A}^{\prime}\right] \delta\left(\mathrm{CH}_{3}\right)_{\mathrm{s}}(50)+\delta\left(\mathrm{CH}_{2}\right)(14)+\delta\left(\mathrm{CH}_{3}\right)_{\mathrm{as}}{ }^{\prime}(12)$} \\
\hline $\begin{array}{l}1413 / 1412 / 1407 / 1404 / \\
1401 / 1396\end{array}$ & 1406 & 124 & {$\left[\mathrm{~A}^{\prime}\right] \mathrm{v}_{2}($ ring $)(32)+\delta\left(\mathrm{CH}_{3}\right)_{\mathrm{s}}(31)+\mathrm{w}\left(\mathrm{CH}_{2}\right)(11)+\delta_{2}$ (ring) $(11)$} \\
\hline $1343 / 1342 / 1337 / 1335$ & 1331 & 45 & {$\left[\mathrm{~A}^{\prime}\right] \delta(\mathrm{NH})(53)+\mathrm{v}_{1}(\mathrm{ring})(25)+\mathrm{v}(\mathrm{C}=\mathrm{O})_{\mathrm{as}}(11)$} \\
\hline $1319 / 1316$ & 1303 & 138 & {$\left[\mathrm{~A}^{\prime}\right] \mathrm{v}_{4}($ ring $)(20)+\mathrm{v}_{1}($ ring $)(19)+\delta(\mathrm{C}=\mathrm{O})_{\mathrm{s}}(17)+\delta(\mathrm{NH})(11)$} \\
\hline $1295 / 1292$ & 1278 & 14 & {$\left[\mathrm{~A}^{\prime}\right] \gamma\left(\mathrm{CH}_{3}\right)^{\prime}(18)+v_{2}\left(\right.$ ring) $(15)+v_{4}($ ring $)(15)+v(\mathrm{NC})(15)$} \\
\hline $1237 / 1235 / 1232$ & 1233 & 35 & {$\left[\mathrm{~A}^{\prime}\right] \mathrm{w}\left(\mathrm{CH}_{2}\right)(60)+\mathrm{v}(\mathrm{NC})(19)$} \\
\hline $1180 / 1176$ & 1178 & 4 & {$\left[\mathrm{~A}^{\prime \prime}\right] \mathrm{tw}\left(\mathrm{CH}_{2}\right)(82)$} \\
\hline 1131 & 1125 & 0.2 & {$\left[\mathrm{~A}^{\prime \prime}\right] \gamma\left(\mathrm{CH}_{3}\right)^{\prime \prime}(80)+\mathrm{tw}\left(\mathrm{CH}_{2}\right)$} \\
\hline $\begin{array}{l}1121 / 1119 / 1116 / 1112 / \\
1108\end{array}$ & 1099 & 103 & {$\left[\mathrm{~A}^{\prime}\right] \mathrm{v}_{1}$ (ring) $(29)+\mathrm{v}_{3}($ ring $)(15)+\gamma\left(\mathrm{CH}_{3}\right)^{\prime}(11)+\delta(\mathrm{NH})(10)$} \\
\hline $1029 / 1028$ & 1020 & 42 & {$\left[\mathrm{~A}^{\prime}\right] \gamma\left(\mathrm{CH}_{3}\right)^{\prime}(44)+v_{2}$ (ring) $(23)+v_{3}($ ring $)(10)$} \\
\hline $995 / 986$ & 990 & 0.2 & {$\left[\mathrm{~A}^{\prime \prime}\right] \gamma\left(\mathrm{CH}_{2}\right)(75)$} \\
\hline $884 / 883$ & 873 & 15 & {$\left[\mathrm{~A}^{\prime}\right] \mathrm{v}_{5}($ ring $)(30)+\delta_{2}($ ring $)(21)+v_{4}($ ring $)(20)$} \\
\hline 816 & 805 & 6 & {$\left[A^{\prime}\right] v_{5}$ (ring) $(24)+v(\mathrm{NC})(19)+v_{3}($ ring $)(19)+v_{2}($ ring $)(16)$} \\
\hline 752 & 739 & 12 & {$\left[\mathrm{~A}^{\prime \prime}\right] \gamma(\mathrm{C}=\mathrm{O} 7)(96)$} \\
\hline 688 & 680 & 7 & {$\left[\mathrm{~A}^{\prime}\right] \delta_{1}\left(\right.$ ring) $(39)+v_{3}($ ring $)(13)+\delta(C=O)_{\text {as }}(13)$} \\
\hline \multirow[t]{2}{*}{$594 / 591 / 588 / 586 / 582$} & 581 & 49 & {$\left[\mathrm{~A}^{\prime \prime}\right] \gamma(\mathrm{C}=\mathrm{O} 9)(70)+\gamma(\mathrm{NH})(29)+\gamma\left(\mathrm{CH}_{2}\right)(12)$} \\
\hline & 580 & 8 & {$\left[\mathrm{~A}^{\prime}\right] \delta_{1}($ ring $)(24)+\delta(\mathrm{C}=\mathrm{O})_{\text {as }}(24)+v_{5}($ ring $)(16)+v_{3}($ ring $)(15)$} \\
\hline $555 / 554$ & 547 & 22 & {$\left[\mathrm{~A}^{\prime}\right] \delta_{2}$ (ring) $(43)+\delta(\mathrm{C}=\mathrm{O})_{\text {as }}(31)+\mathrm{v}(\mathrm{NC})(14)$} \\
\hline $530 / 527$ & 526 & 77 & {$\left[\mathrm{~A}^{\prime \prime}\right] \gamma(\mathrm{NH})(76)$} \\
\hline n.i. & 377 & 22 & {$\left[\mathrm{~A}^{\prime}\right] \delta(\mathrm{C}=\mathrm{O})_{\mathrm{s}}(65)+v_{1}(\mathrm{ring})(12)$} \\
\hline n.i. & 280 & 2 & {$\left[\mathrm{~A}^{\prime}\right] \delta(\mathrm{NC})(76)+\mathrm{v}_{2}(\mathrm{ring})(10)+\delta(\mathrm{C}=\mathrm{O})_{\text {as }}(10)$} \\
\hline n.i. & 191 & 1 & {$\left[\mathrm{~A}^{\prime \prime}\right] \tau_{1}$ (ring) $(102)$} \\
\hline n.i. & 157 & 6 & {$\left[\mathrm{~A}^{\prime \prime}\right] \gamma(\mathrm{NC})(43)+\tau_{2}$ (ring) $(24)+\tau\left(\mathrm{CH}_{3}\right)(22)+\tau_{1}($ ring $)(11)$} \\
\hline n.i. & 119 & 2 & {$\left[\mathrm{~A}^{\prime \prime}\right] \tau_{2}$ (ring) $(72)+\tau\left(\mathrm{CH}_{3}\right)(38)$} \\
\hline n.i. & 79 & 0.4 & {$\left[\mathrm{~A}^{\prime \prime}\right] \gamma(\mathrm{NC})(88)+\tau\left(\mathrm{CH}_{3}\right)(36)$} \\
\hline
\end{tabular}

${ }^{a}$ Key (a) See Table S1 (Supporting Information) for definition of the symmetry coordinates and Scheme 1 for atom numbering. Abbreviations: $\mathrm{w}$, wagging; tw, twisting; $\gamma$, rocking; $\nu$, stretching; $\delta$, bending; $\tau$, torsion; s, symmetric; as, antisymmetric. (b) Wavenumbers in $\mathrm{cm}^{-1}$; n.obs., not observed; n.i., not investigated. (c) IR intensities in $\mathrm{km} \mathrm{mol}^{-1}$. (d) PED's lower than $10 \%$ are not shown; symmetry of the vibrations are given in square brackets. (e) The $\nu(\mathrm{CH} 3)$ s mode participates in a Fermi resonance interaction with the first overtone of the $\delta(\mathrm{CH} 3)$ as" mode, whose fundamental is observed at $1457 / 1455 \mathrm{~cm}^{-1}$ (matrix-site split band); other overtones and combination tones observed in the $\mathrm{CH}$ stretching region of the spectrum appear at $2983(2 \times 1492), 2868(1455+1412), 2846(2 \times 1426)$ and $2802(2 \times 2808) \mathrm{cm}^{-1}$.

reduced intensity, and the proposed assignments are tentative (the spectra obtained for the neat solid compound do not help very much to increase the certainty of the assignments because in these cases the $\mathrm{CH}$ stretching bands appear superimposed to the strong downshifted due to hydrogen bonding $\mathrm{NH}$ stretching features; see Figure S2). On the other hand, the assignments for the $\mathrm{CH}$ bending and rocking modes are straightforward (see Table 5 and Figure 2).

The skeletal vibrations could also be assigned with ease, because they were very well predicted by the calculations. Two of the ring stretching modes were predicted by the calculations to have a relevant contribution from the $\delta(\mathrm{NH})$ coordinate (bands calculated at 1303 and $1099 \mathrm{~cm}^{-1}$, mainly associated with the $\nu_{4}$ (ring) and $\nu_{1}$ (ring) coordinates; see Tables 5 and S1). Accordingly, the corresponding observed bands (1319/ 1316 and multiplet at ca. $1108-1120 \mathrm{~cm}^{-1}$ ) were also found to exhibit larger frequency shifts in going from the isolated monomer to the neat solid compound (details will be provided below).
UV-Induced Photolysis of Matrix-Isolated 1-MH. The matrix isolated $1-\mathrm{MH}$ monomer was submitted to UVirradiation using two different experimental approaches, in order to investigate its photochemistry. Irradiation was performed through the outer quartz window of the cryostat either with broadband UV light produced by a $\mathrm{Hg}(\mathrm{Xe})$ lamp or narrowband ( $\lambda=230 \mathrm{~nm}$; fwhm $0.2 \mathrm{~cm}^{-1}$ ) UV laser/MOPO light. In the broadband irradiation experiments, the $\mathrm{Hg}(\mathrm{Xe})$ lamp was fitted with a water filter $(8 \mathrm{~cm}$ long) to absorb heat, and appropriate UV-cutoff filters were used to select wavelength range $(\lambda>367,328,295,234 \mathrm{~nm})$. Only when the 234 nm filter was used, was the broadband irradiation found to lead to photochemical transformation of the reactant. Under these conditions, after $\sim 7 \mathrm{~h}$ of consecutive irradiation the amount of $1-\mathrm{MH}$ in the sample reduced to ca. $1 / 4$ of the initial. The narrowband irradiation $(\lambda=230 \mathrm{~nm})$ was found to be considerably more efficient than the broadband one, though the observed spectral changes indicate that the photoinduced transformations are the same in the two types of experiments. 
Scheme 3. Photoinduced Fragmentation Pathways of 1-MH in an Argon Matrix upon $230 \mathrm{~nm}$ Excitation $^{a}$

(a)

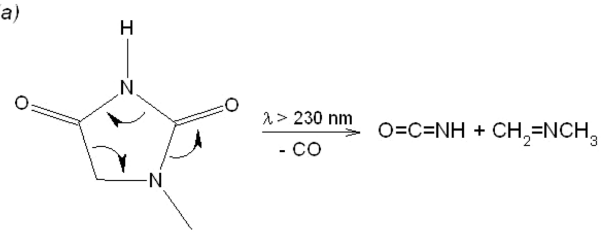

(b)

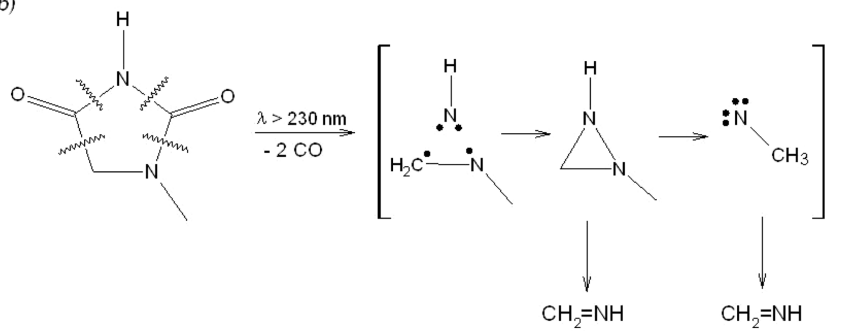

${ }^{a}$ Suggested intermediate species in the brackets were not observed (see text).
Upon laser/MOPO irradiation of the sample at $\lambda=230 \mathrm{~nm}$, the initial amount of $1-\mathrm{MH}$ was reduced to $1 / 4$ after only about $1 \mathrm{~h}$ irradiation.

The results of the performed photochemical experiments are summarized in Scheme 3, Figure 3 and Table 6. According to the observations, the $230 \mathrm{~nm}$ induced photolysis of matrix isolated 1-MH occurs via two different pathways, which lead to fragmentation to $(a) \mathrm{OCNH}+\mathrm{CO}+\mathrm{H}_{2} \mathrm{C}=\mathrm{NCH}_{3}$ and $(b)$ $2 \mathrm{CO}+2 \mathrm{H}_{2} \mathrm{C}=\mathrm{NH}$. We were not able to capture any reaction intermediate, so that the precise mechanisms of fragmentation can only be tentatively proposed.

Pathway $(a)$ is probably a concerted process where the weak $\mathrm{C} 2-\mathrm{N} 3$ and $\mathrm{C} 4-\mathrm{C} 5$ bonds are cleaved, yielding an isocyanic acid molecule $(\mathrm{OCNH})$, and triggering the cleavage of the stronger $\mathrm{N} 1-\mathrm{C} 2$ bond with production of $\mathrm{CO}$ and $\mathrm{N}$-methylmethylenimine $\left(\mathrm{H}_{2} \mathrm{C}=\mathrm{NCH}_{3}\right)$. Note that this pattern of fragmentation respects the theoretical indication (see results of the AIM analysis discussed before) that the most strained fragment in the 1-MH molecule corresponds to the C5C4N3C2 moiety (as show before, with $\sim 67 \%$ of the total ring strain), i.e., that the elimination of isocyanic acid
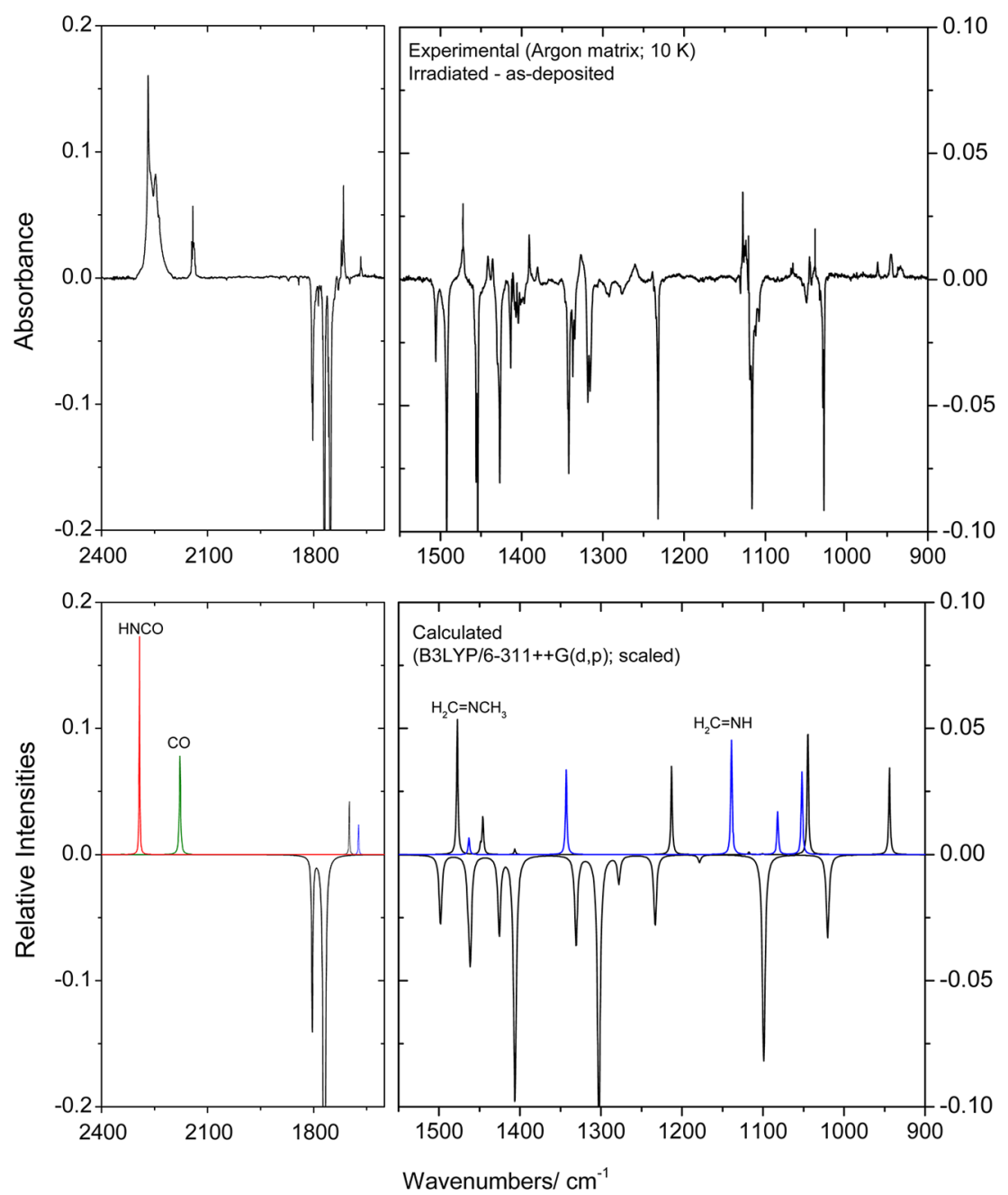

Figure 3. Experimental infrared difference spectrum: irradiated 1-MH matrix $(\lambda=230 \mathrm{~nm} ; 1 \mathrm{~h})$ minus as-deposited 1-MH matrix (top) and simulated difference spectrum based on the B3LYP/6-311++G(d,p) calculated (scaled) spectra of 1-MH, $\mathrm{HNCO}, \mathrm{CO}, \mathrm{H}_{2} \mathrm{C}=\mathrm{NH}_{2}$ and $\mathrm{H}_{2} \mathrm{C}=\mathrm{NCH}_{3}$ (bottom). The intensities of the different photoproducts in the simulated spectrum were multiplied by arbitrary factors to allow an easier comparison with the experimental data. 
Table 6. Infrared Spectrum of the Photolyzed 1-MH in Argon Matrix (10 K, $X=230 \mathrm{~nm}, 1 \mathrm{~h}), \mathrm{B} 3 \mathrm{LYP} / 6-311 \mathrm{G}+$ $+(\mathrm{d}, \mathrm{p})$ Calculated Spectra for the Observed Photoproducts and Relevant Literature data ${ }^{a}$

\begin{tabular}{|c|c|c|c|c|c|}
\hline & & \multicolumn{2}{|c|}{ calculated } & \multicolumn{2}{|c|}{ experimental } \\
\hline & & freq & $I_{\mathrm{IR}}$ & this study & lit. freq ${ }^{b}$ \\
\hline \multicolumn{6}{|c|}{ Isocyanic Acid } \\
\hline 1 & $\nu(\mathrm{NH})$ & 3531 & 170 & 3339,3336 & 3517,3506 \\
\hline 2 & $\nu(\mathrm{NCO})_{\mathrm{as}}$ & 2292 & 783 & $\begin{array}{l}2268,2262,2247 \\
2238\end{array}$ & 2259 \\
\hline 3 & $\nu(\mathrm{NCO})_{\mathrm{s}}$ & 1311 & 1 & n.o. & n.o. \\
\hline 4 & $\delta(\mathrm{HNC})$ & 749 & 200 & 730 & 770 \\
\hline 5 & $\delta(\mathrm{NCO})$ & 557 & 97 & 567 & 574 \\
\hline 6 & $\gamma(\mathrm{NCO})$ & 620 & 4 & 605 & n.o. \\
\hline & $4+5$ & & & 1327 & 1315 \\
\hline \multicolumn{6}{|c|}{ Carbon Monoxide } \\
\hline & $\nu(\mathrm{CO})$ & 2167 & 89 & $2145-2134$ & $\begin{array}{l}2138 \\
\quad \text { (monomer) }\end{array}$ \\
\hline \multicolumn{6}{|c|}{$N$-Methylmethylenimine } \\
\hline 1 & $\nu\left(\mathrm{CH}_{2}\right)_{\text {as }}$ & 3064 & 28 & 3014 & \\
\hline 2 & $\nu\left(\mathrm{CH}_{3}\right)_{\mathrm{as}}{ }^{\prime \prime}$ & 3021 & 16 & 2977 & \\
\hline 3 & $\nu\left(\mathrm{CH}_{3}\right)_{\mathrm{as}}{ }^{\prime}$ & 3003 & 24 & 2969 & \\
\hline 4 & $\nu\left(\mathrm{CH}_{2}\right)_{\mathrm{s}}$ & 2916 & 90 & 2869 & \\
\hline 5 & $\nu\left(\mathrm{CH}_{3}\right)_{\mathrm{s}}$ & 2905 & 44 & 2862 & \\
\hline 6 & $\nu(\mathrm{CN})$ & 1699 & 19 & 1721,1716 & \\
\hline 7 & $\delta\left(\mathrm{CH}_{2}\right)$ & 1477 & 23 & 1472 & \\
\hline 8 & $\delta\left(\mathrm{CH}_{3}\right)_{\mathrm{as}}^{\prime}$ & 1449 & 2 & 1441 & \\
\hline 9 & $\delta\left(\mathrm{CH}_{3}\right)_{\mathrm{as}}^{\prime \prime}$ & 1446 & 6 & 1436 & \\
\hline 10 & $\delta\left(\mathrm{CH}_{3}\right)_{\mathrm{s}}$ & 1406 & 1 & $\begin{array}{l}1412,1411,1405 \\
1403\end{array}$ & \\
\hline 11 & $\mathrm{w}\left(\mathrm{CH}_{2}\right)$ & 1213 & 15 & $1260,1239,1237$ & \\
\hline 12 & $\gamma\left(\mathrm{CH}_{3}\right)_{\mathrm{as}}^{\prime \prime}$ & 1117 & 1 & n.o. & \\
\hline 13 & $\gamma\left(\mathrm{CH}_{3}\right)_{\mathrm{as}}^{\prime}$ & 1101 & $<1$ & n.o. & \\
\hline 14 & $\gamma\left(\mathrm{CH}_{2}\right)$ & 1045 & 22 & 1039,1034 & \\
\hline 15 & $\nu\left(\mathrm{NCH}_{3}\right)$ & 944 & 15 & $962,946,935$ & \\
\hline 16 & $\tau(\mathrm{C}-\mathrm{N})$ & 682 & 1 & 655 & \\
\hline 17 & $\delta(\mathrm{CNC})$ & 469 & 6 & 495 & \\
\hline 18 & $\tau\left(\mathrm{CH}_{3}\right)$ & 212 & 9 & n.i. & \\
\hline \multicolumn{6}{|c|}{ Methylenimine } \\
\hline 1 & $\nu(\mathrm{NH})$ & 3286 & 2 & $\begin{array}{l}3301,3298,3295 \\
3292\end{array}$ & $3263^{c}$ \\
\hline 2 & $\nu\left(\mathrm{CH}_{2}\right)_{\mathrm{as}}$ & 3050 & 33 & 3014 & $3085,^{d} 3036^{e}$ \\
\hline 3 & $\nu\left(\mathrm{CH}_{2}\right)_{\mathrm{s}}$ & 2951 & 53 & 2932 & $2926^{e}$ \\
\hline 4 & $\nu(\mathrm{CN})$ & 1673 & 25 & 1666 & $1650,^{d} 1641^{e}$ \\
\hline 5 & $\delta\left(\mathrm{CH}_{2}\right)$ & 1463 & 7 & 1459,1458 & $1460,^{d} 1453^{e}$ \\
\hline 6 & $\delta(\mathrm{HNC})$ & 1343 & 35 & 1391,1380 & $1358,^{d} 1348^{e}$ \\
\hline 7 & $\mathrm{w}\left(\mathrm{CH}_{2}\right)$ & 1139 & 47 & $\begin{array}{l}1128,1125,1122 \text {, } \\
1120\end{array}$ & $1113^{d} 1123^{e}$ \\
\hline 8 & $\tau(\mathrm{C}-\mathrm{N})$ & 1083 & 18 & 1068,1066 & $1072,^{d} 1063^{e}$ \\
\hline 9 & $\gamma\left(\mathrm{CH}_{2}\right)$ & 1052 & 34 & 1046,1044 & $1040,^{d} 1059^{e}$ \\
\hline
\end{tabular}

${ }^{a}$ Wavenumbers in $\mathrm{cm}^{-1}$; IR intensities in $\mathrm{km} \mathrm{mol}^{-1}$. Abbreviations: $\mathrm{s}$, symmetric; as, antisymmetric; w, wagging; $\nu$, stretching; $\delta$, in-plane bending; $\gamma$, rocking; $\tau$, torsion; n.o., not observed; n.i., not investigated. ${ }^{b}$ Literature data for isolated monomers: isocyanic acid, ${ }^{44}$ carbon monoxide, ${ }^{45}$ methylenimine: ${ }^{c}$ Reference $46 .{ }^{d}$ Reference $47 .{ }^{e}$ Reference 48.

(specifically the fragment $\mathrm{H} 8 \mathrm{~N} 3 \mathrm{C} 4 \mathrm{O} 9$ ) should be a favored fragmentation process in 1-MH.

Note that detachment of isocyanic acid from 1-MH has also been observed in other types of experiments, namely electronionization mass spectrometry. ${ }^{19,49-51}$ Furthermore, pathway (a) is identical to that previously reported in case of the 230

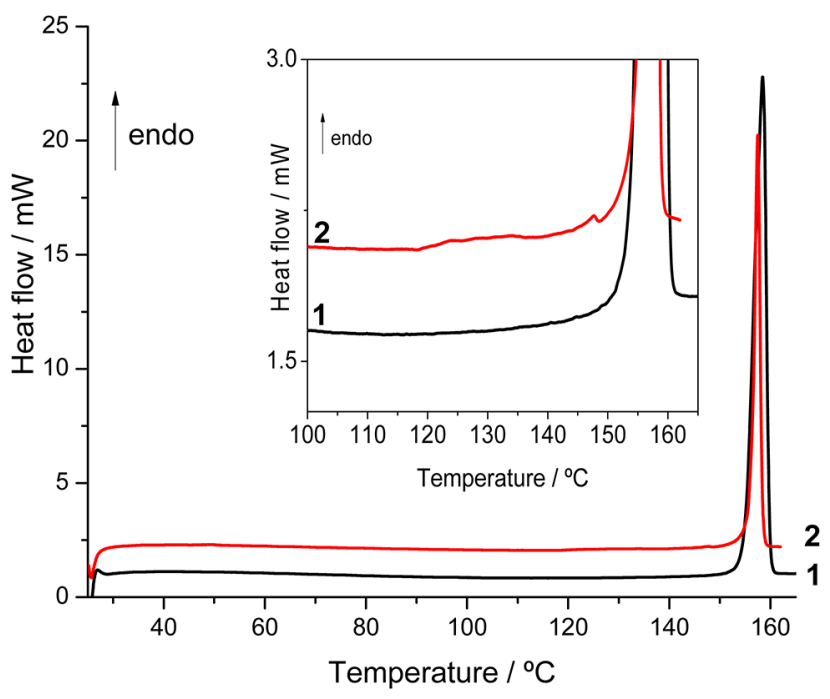

Figure 4. 1-MH DSC heating curves from 25 to $162{ }^{\circ} \mathrm{C}, \beta=10{ }^{\circ} \mathrm{C}$ $\mathrm{min}^{-1}$. (1) Original 1-MH substance (polymorph I), ${ }^{19}$ mass $m=1.91$ mg. (2) 1-MH sample obtained by sublimation (at $T=100{ }^{\circ} \mathrm{C}, p=$ $103 \mathrm{~Pa}$, coldfinger at about $20^{\circ} \mathrm{C}$, polymorph II), $m=0.79 \mathrm{mg}$.

$\mathrm{nm}$ photofragmentation of the parent hydantoin molecule isolated in and argon matrix and subjected to identical experimental conditions. ${ }^{17}$

Pathway $(b)$, on the other hand, is most probably a more complex process, where extrusion of two molecules of $\mathrm{CO}$ should led to formation of the $\mathrm{NH}$ radical, which then reacts with the remaining fragment $\left(\mathrm{CH}_{2} \mathrm{NCH}_{3}\right)$ to produce two methylenimine molecules. Such process may eventually occur through a cyclic $\mathrm{N}$-methyl-diaziridine intermediate resulting from radical recombination. Whatever is the real mechanism, methyl nitrene shall be involved (which shall convert to methylenimine by $[1,2]-\mathrm{H}$ shift), but this species was also not detected in the present experiments.

The key-products of $(a)$ and $(b)$ are HCON and $N$ methylmethylenimine in one side and methylenimine in the other, because $\mathrm{CO}$ is produced in both pathways. As shown in Figure 3 and Table 6, the presence of these products in the photolyzed 1-MH matrix is doubtless. The small differences found in the positions of some bands of these species compared to literature data ${ }^{44-48}$ result from the fact that in the present case the molecules are interacting in the same matrix cage.

Thermal Analysis Investigation of 1-MH. The crystalline structure of the purchased sample of $1-\mathrm{MH}$ was identified as that described by Puszyńska-Tuszkanow and co-workers, hereafter polymorph $\mathrm{I}^{19}$ (See X-ray powder diffractogram in Figure S3, Supporting Information). According to the performed DSC studies, the melting of the purchased sample of $1-\mathrm{MH}$, occurs at $T_{\text {fus }}=(155.7 \pm 0.7){ }^{\circ} \mathrm{C}$, with an enthalpy of fusion $\Delta_{\text {fus }} H=(21.5 \pm 0.3) \mathrm{kJ} \mathrm{mol}^{-1}$ (curve 1, Figure 4). In the heating process, no other events were observed, as proved also by the thermomicroscopy images in Figure 5, part 1).

Another 1-MH sample was obtained by sublimation at $T=$ $100{ }^{\circ} \mathrm{C}, p=103 \mathrm{~Pa}$, using the coldfinger technique, with water at about $20^{\circ} \mathrm{C}$ as the freezing fluid. The crystalline structure of this new sample, crystals with uniform acicular habit, differs from that of polymorph I, as supported by the ATR spectra presented in Figure $6\left(1600-500 \mathrm{~cm}^{-1}\right.$ region; Figure S4 for $3600-1600 \mathrm{~cm}^{-1}$ range) and by the comparison of the X-ray powder diffractogram of the new polymorph (Figure S5) with that of polymorph I (see Figure S3). Moreover, on heating the 
1

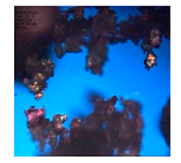

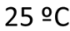

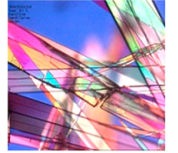

25 으

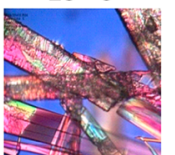

$129 \stackrel{\circ}{ } \mathrm{C}$

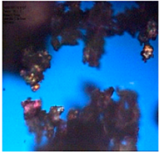

$90 \div \mathrm{C}$

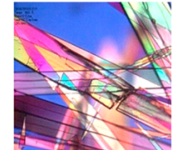

$90 \stackrel{\circ}{ } \mathrm{C}$

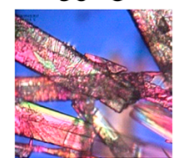

$131 \stackrel{\circ}{ } \mathrm{C}$

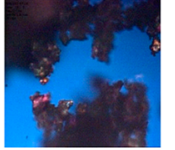

$136 \circ \mathrm{C}$

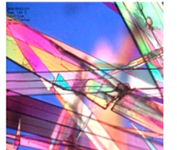

$110 \stackrel{\circ}{\mathrm{C}}$

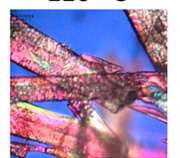

$136 \stackrel{\circ}{\circ}$

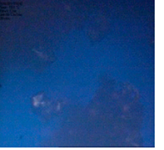

156 으

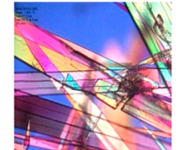

$119 \stackrel{\circ}{\circ} \mathrm{C}$

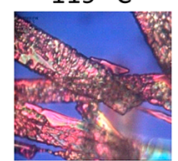

$156 \stackrel{\circ}{\circ}$

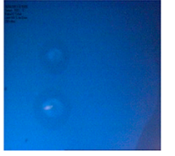

$158 \stackrel{\circ}{\circ}$

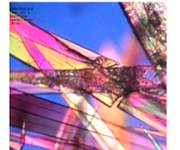

$125 \stackrel{\circ}{\circ} \mathrm{C}$

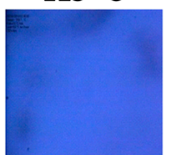

$158 \stackrel{\circ}{\circ}$

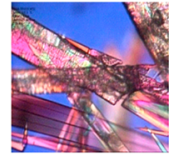

$127 \stackrel{\circ}{\circ} \mathrm{C}$

Figure 5. Polarized light thermomicroscopy images collected in 1-MH heating processes from 25 to $162{ }^{\circ} \mathrm{C}, \beta=10^{\circ} \mathrm{C}$ min ${ }^{-1}$, amplification $200 \mathrm{X}$. (1) Original 1-MH substance (polymorph I). ${ }^{19}$ (2) 1-MH sample obtained by sublimation $\left(\right.$ at $T=100{ }^{\circ} \mathrm{C}, p=103 \mathrm{~Pa}$, coldfinger at about $25^{\circ} \mathrm{C}$ ), polymorph II.

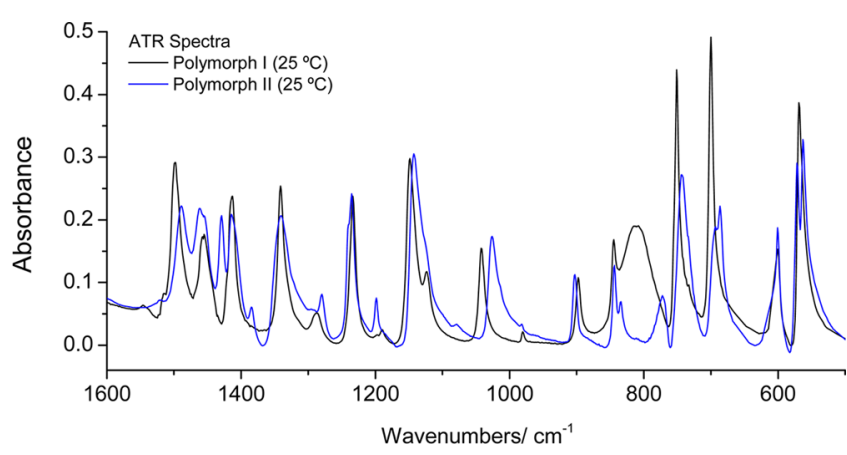

Figure 6. $1-\mathrm{MH}$ attenuated reflectance IR spectra $\left(1600-500 \mathrm{~cm}^{-1}\right.$ range; the $3600-1600 \mathrm{~cm}^{-1}$ region is shown in Figure S4): original 1MH substance (polymorph I) ${ }^{19}$ (black line); 1-MH sample obtained by sublimation (at $T=100^{\circ} \mathrm{C}, p=103 \mathrm{~Pa}$, coldfinger at about $25^{\circ} \mathrm{C}$; polymorph II) (blue line).

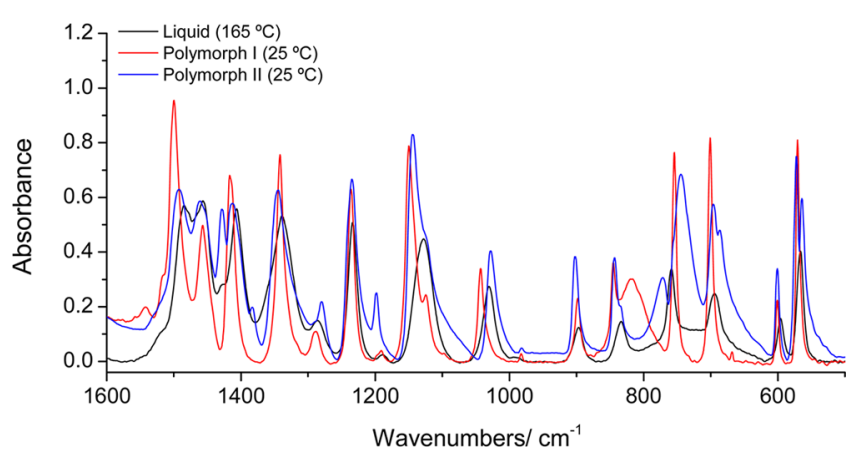

Figure 7. Infrared spectra $\left(1600-500 \mathrm{~cm}^{-1}\right.$ region; the $3600-1600$ $\mathrm{cm}^{-1}$ region is shown in Figure S6) of liquid 1-MH, at $165{ }^{\circ} \mathrm{C}$ (black line), and of the two crystalline polymorphs of the compound at room temperature $\left(25^{\circ} \mathrm{C}\right)$ (polymorph I, red line; polymorph II, blue line).

new solid form, II, a low energy solid-solid transition takes place, extending from about 110 to $135^{\circ} \mathrm{C}$, as clearly evidenced by PLTM images in Figure 5, part 2, and also apparent in curve 2 in the inset of Figure 4. The solid-solid transition gives rise to polymorph I, as the thermodynamic values obtained for the fusion process are indistinguishable from those of this form. This conclusion is also supported by IR spectroscopy, as detailed below.
The infrared spectra of both purchased and obtained by sublimation at $\mathrm{T}=100{ }^{\circ} \mathrm{C}$ crystalline samples diluted in $\mathrm{KBr}$ pellets were recorded at room temperature (see Figure 7 and Figure S5, for $1600-500$ and $3600-1600 \mathrm{~cm}^{-1}$ spectral regions, respectively). These spectra are identical to the corresponding ATR spectra shown in Figure 6 and Figure S4, demonstrating that the process of preparation of the $\mathrm{KBr}$ pellets did not lead to any structural change. Polymorph II sample was then submitted to a temperature program similar to those used in the DSC and thermomicroscopy experiments. Figure 8 summarizes the observed changes in the spectra in two representative spectral regions along the temperature variation experiments. These two spectral regions (showing the bands due to $\gamma\left(\mathrm{CH}_{3}\right)^{\prime}\left(1060-980 \mathrm{~cm}^{-1}\right)$, and $\delta(\mathrm{C}=\mathrm{O} 7)$ and $\delta_{2}$ (ring) modes $\left(590-540 \mathrm{~cm}^{-1}\right)$, respectively) were chosen because they are very much sensitive to phase changes, but do not vary too much with temperature for a given phase, so that phase transitions can be easily detected (for example, the spectral region corresponding to the $\gamma(\mathrm{NH})$ vibration, between 850 and $600 \mathrm{~cm}^{-1}$, is the most sensitive region to structural changes, but the large shifts with temperature in the same phase makes this region less illustrative to phase transition observations). In the two chosen spectral regions, the two polymorphs have quite diverse vibrational signatures, with polymorph I exhibiting two single bands at 1043 and $571 \mathrm{~cm}^{-1}$, while polymorph II gives rise to a band at $1028 \mathrm{~cm}^{-1}$ and a doublet at $572 / 564 \mathrm{~cm}^{-1}$. In consonance with the DSC and PLTM results, the IR spectroscopy results clearly show that, upon heating, polymorph II converts into polymorph I, which then melts at about $155^{\circ} \mathrm{C}$, as expected for this polymorph. As shown in Figure 8, the spectrum obtained at $155{ }^{\circ} \mathrm{C}$ reveals a still incomplete melting, while the spectrum registered at 165 ${ }^{\circ} \mathrm{C}$ corresponds to that of liquid 1-MH (see Figure 7 and Figure S4 for full mid-IR spectrum of the liquid). Also as in the DSC and PLTM experiments, the solid-solid II $\rightarrow$ I transition was found to take place in an extended range of temperature. However, the process could be spectroscopically detected to have already started around $95{ }^{\circ} \mathrm{C}$ (see Figure 8), a somewhat lower temperature compared to those found in the DSC and PLTM experiments. This may be assigned to the dissimilar experimental conditions in the different experiments.

The band assignments for the room temperature IR spectra of the two polymorphs of $1-\mathrm{MH}$ and for the liquid phase of the 

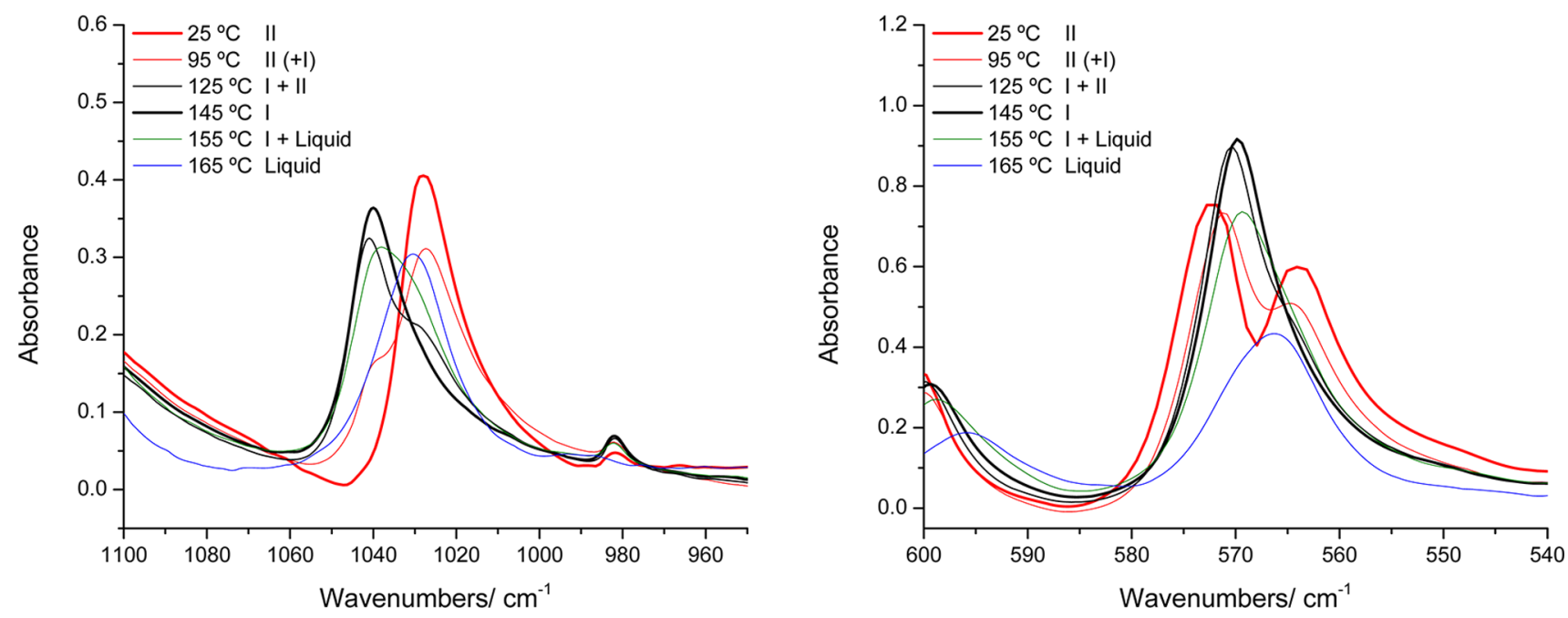

Figure 8. Infrared spectra (selected spectral regions) showing the evolution with temperature of a sample of polymorph II of 1-MH.

Table 7. Infrared Bands $\left(\mathrm{cm}^{-1}\right)$ of Liquid $1-\mathrm{MH}$, at $165^{\circ} \mathrm{C}$, and of the Two Observed Polymorphs (I and II) of the Compound (in KBr Pellet; $T=25{ }^{\circ} \mathrm{C}$ ), with Assignments ${ }^{a}$

\begin{tabular}{|c|c|c|c|}
\hline \multirow{2}{*}{$\begin{array}{l}\text { Liquid } \\
\left(165^{\circ} \mathrm{C}\right) \\
\text { Freq }\end{array}$} & \multicolumn{2}{|c|}{$\operatorname{Crystal}\left(25^{\circ} \mathrm{C}\right)$} & \multirow[b]{2}{*}{ Assignment $^{a}$} \\
\hline & $\begin{array}{l}\text { Polymorph I } \\
\text { Freq }\end{array}$ & $\begin{array}{l}\text { Polymorph II } \\
\text { Freq }\end{array}$ & \\
\hline $3244 / 3076 /$ & $3202 / 3142 /$ & $3257 / 3192 /$ & $v(\mathrm{NH})$ \\
\hline \multirow{2}{*}{$2938 / 2756$} & $3045 / 2819 /$ & $3128 / 3072 /$ & \\
\hline & $2776 / 2744$ & $\begin{array}{l}3047 / 2752 / \\
2723\end{array}$ & \\
\hline 29627 & 2983 & 2984 & $v\left(\mathrm{CH}_{3}\right)_{\mathrm{as}}{ }^{\prime}$ \\
\hline 2962$\}$ & 2957 乙 & 2952 & $\mathrm{v}\left(\mathrm{CH}_{3}\right)_{\mathrm{as}} "$ \\
\hline 2962 J & $2957\}$ & 2939 & $v\left(\mathrm{CH}_{2}\right)_{\mathrm{a}}$ \\
\hline 2927 & 2933 & 2928 & $v\left(\mathrm{CH}_{2}\right)_{\mathrm{s}}$ \\
\hline 2883 & 2886 & 2886 & $\mathrm{v}\left(\mathrm{CH}_{3}\right)_{\mathrm{s}}$ \\
\hline $1796 / 1770$ & $1800 / 1770$ & $1803 / 1770$ & $v(\mathrm{C}=\mathrm{O} 9)$ \\
\hline \multirow[t]{2}{*}{1722} & $1748 / 1727 /$ & $1751 / 1728 /$ & $v(\mathrm{C}=\mathrm{O} 7)$ \\
\hline & $1709 / 1688$ & $1709 / 1687$ & \\
\hline 1517 & 1516 & 1517 & $\delta\left(\mathrm{CH}_{3}\right)_{\text {as }}{ }^{\prime}$ \\
\hline 1485 & 1500 & 1489 & $\delta(\mathrm{NH})$ \\
\hline 1470 & 1457 & 1462 & $\delta\left(\mathrm{CH}_{3}\right)_{\mathrm{as}}{ }^{\prime \prime}$ \\
\hline 1458 & 1452 & 1456 & $\delta\left(\mathrm{CH}_{2}\right)$ \\
\hline 1428 & 1421 & 1427 & $\delta\left(\mathrm{CH}_{3}\right)_{\mathrm{s}}$ \\
\hline 1407 & $1417 / 1415$ & $1414 / 1383$ & $v_{2}$ (ring) \\
\hline 1339 & 1342 & 1343 & $\mathrm{v}_{4}(\text { ring })^{b}$ \\
\hline 1287 & 1289 & $1291 / 1280$ & $v(\mathrm{NC})$ \\
\hline 1234 & 1236 & $1240 / 1235$ & $\left.\mathrm{w}\left(\mathrm{CH}_{2}\right)\right)$ \\
\hline 1188 & $1198 / 1191$ & 1198 & $\operatorname{tw}\left(\mathrm{CH}_{2}\right)$ \\
\hline 1130$\}$ & $1125 / 1114$ & 1125 & $\gamma\left(\mathrm{CH}_{3}\right)^{\prime \prime}$ \\
\hline 1130$\}$ & $1150 / 1145$ & 1145 & $v_{1}(\text { ring })^{b}$ \\
\hline 1030 & 1043 & 1028 & $\gamma\left(\mathrm{CH}_{3}\right)^{\prime}$ \\
\hline 992 & 983 & 982 & $\gamma\left(\mathrm{CH}_{2}\right)$ \\
\hline 898 & 898 & 901 & $v_{5}$ (ring) \\
\hline 834 & 845 & $844 / 835$ & $v_{3}$ (ring) \\
\hline 734 & 817 & 771 & $\gamma(\mathrm{NH})$ \\
\hline 759 & 754 & 745 & $\gamma(\mathrm{C}=07)$ \\
\hline 694 & 701 & $700 / 687$ & $\delta_{1}$ (ring) \\
\hline 596 & 601 & 601 & $\gamma(\mathrm{C}=09)$ \\
\hline 572 & 571 乙 & 572 & $\delta(\mathrm{C}=\mathrm{O} 7)$ \\
\hline 567 & $571\}$ & 564 & $\delta_{2}$ (ring) \\
\hline
\end{tabular}

${ }^{a}$ Key: (a) See Scheme 1 for atom numbering; assignments correspond to approximate descriptions of the vibrations chosen as the main coordinate contributing to the vibration (avoiding repetition) and are based on the PED's obtained for the isolated monomer (see Table 5); abbreviations: $\mathrm{w}$, wagging; tw, twisting; $\gamma$, rocking; $\nu$, stretching; $\delta$, bending; $\tau$, torsion; s, symmetric; as, antisymmetric. (b) Also with a significant contribution from the $\delta(\mathrm{NH})$ coordinate.

compound (at $165{ }^{\circ} \mathrm{C}$ ) are collected in Table 7. The interpretation of these spectra was facilitated by the experiments carried out for solid films of the neat compound at low temperature, described below, where the intrinsic resolution of the bands is, as it could be expected, considerably better than at room and higher temperature. The assignments for neat $1-\mathrm{MH}$ in the different phases considered in the present investigation were also facilitated by comparison of the corresponding spectra with those obtained for the matrix-isolated compound and predicted by the calculations. This comparison was found particularly useful for identification of the bands associated with the $\mathrm{NH}$ hydrogen-bond donor fragment, which could be 

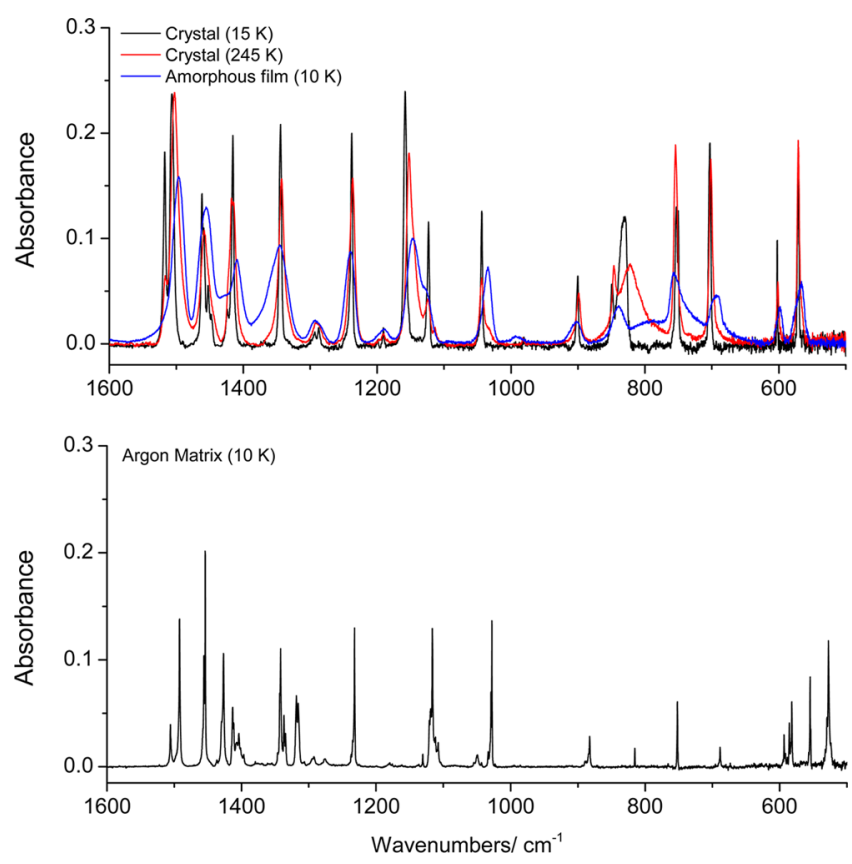

Figure 9. Infrared spectra $\left(1600-500 \mathrm{~cm}^{-1}\right.$ region; the $3600-1600$ $\mathrm{cm}^{-1}$ region is shown in Figure S2) of the amorphous film of neat solid $1-\mathrm{MH}$, at $10 \mathrm{~K}$ (blue line), and of the crystalline film of the compound at $245 \mathrm{~K}$ (after annealing of the amorphous film; red line) and at $15 \mathrm{~K}$ (after recooling; black line) (top), and infrared spectrum of the matrix isolated monomers of 1-MH (argon matrix, $10 \mathrm{~K}$ ) (bottom).

anticipated to be very much sensitive to both phase and temperature changes.

Figure 9 shows the $1600-500 \mathrm{~cm}^{-1}$ spectral region of the spectra of the amorphous solid film of 1-MH resulting from fast cooling of the vapor of the compound onto a CsI substrate kept $10 \mathrm{~K}$, and of the crystalline phase formed upon warming of this film (at $245 \mathrm{~K}$, and after recooling down to $15 \mathrm{~K}$ ). The highfrequency regions $\left(3600-1600 \mathrm{~cm}^{-1}\right)$ of these spectra are given in Figure S2. As expected, the spectrum of the amorphous solid looks very much like that of the liquid sample (see Figures 7 and S6). On the other hand, the spectrum of the crystalline form resulting from warming the amorphous phase and obtained at $245 \mathrm{~K}$ is identical to that of polymorph I obtained at room temperature, with the minor differences between the two spectra (specifically the wider bandwidths exhibited by the room temperature spectrum) being consequence of only temperature effects. The spectral changes observed during the recooling of the crystalline sample down to $15 \mathrm{~K}$ were found to be continuous and perfectly reversible in subsequent warmingcooling cycles. These changes can be assigned to a progressive decrease of vibrational amplitudes upon temperature lowering and strengthening of intermolecular interactions, leading to an increase of ordering in the crystal. Without any doubt, no phase change occurred during this process and the spectrum of the crystalline 1-MH at $15 \mathrm{~K}$ shown in Figure 9 (and Figure S2) thus corresponds to that of a highly ordered polymorph $\mathrm{I}$.

It is worth noticing that all spectra of the neat 1-MH phases resemble very much that obtained for the matrix-isolated compound, except in what concerns the bands associated with the $\mathrm{NH}$ group, which acts as $\mathrm{H}$-bond donor in the neat condensed phases. This result indicates that the prevalent hydrogen bonding intermolecular interactions do not perturb extensively the intramolecular potential, except for the $\mathrm{NH}$ donor moiety. On the other hand, the pronounced effects of the H-bonding interactions on the vibrations of the $\mathrm{NH}$ group are clearly visible in the spectra. In the $\nu(\mathrm{NH})$ stretching region, the usual band broadening, intensification and frequency downshift are observed (see Figures S2 and S6). In case of the $\mathrm{NH}$ bending modes (in plane bending, $\delta(\mathrm{NH})$, and out-of-plane rocking, $\gamma(\mathrm{NH})$ ) band broadening and intensification were also noticed to occur upon $\mathrm{H}$-bond formation, accompanied by the expected shift of frequency to higher wavenumbers. ${ }^{52,53}$

Table 8 shows the assignments for the bands in the spectra of the low temperature amorphous phase and polymorph I at 15 and $245 \mathrm{~K}$ (shown in Figures 9 and S2), and the observed frequency shifts in relation to the position of bands in the spectrum of the matrix-isolated 1-MH. It can be seen that the largest shifts occur for the $\nu(\mathrm{NH}), \delta(\mathrm{NH})$, and $\gamma(\mathrm{NH})$ bands, which amount to ca. $-530,60$ and $270-300 \mathrm{~cm}^{-1}$ (average values in case of more than one band ascribed to the same mode), respectively. All other bands show small shifts, with the following exceptions: $(i)$ bands ascribed to $\nu_{4}$ (ring) and $\nu_{1}$ (ring), with shifts of ca. 20 and $40 \mathrm{~cm}^{-1}$, respectively, which correspond in fact to modes with significant contributions from the $\delta(\mathrm{NH})$ coordinate (see Table 5 for detailed descriptions of the vibrations); (ii) the bands associated with the stretching vibration of the carbonyl group of $1-\mathrm{MH}$ which is more prone to participate in $\mathrm{H}$-bonding, $\nu(\mathrm{C}=\mathrm{O} 7)$, which exhibit a down shift of ca. $40 \mathrm{~cm}^{-1}$ (according to the X-ray data, ${ }^{19}$ in polymorph I, O7 is indeed involved in the dominant $\mathrm{N}-\mathrm{H} \cdots \mathrm{O} 7 \mathrm{H}$-bond interaction, while $\mathrm{O} 9$ is only involved in weak $\mathrm{H}$-bond-type $\mathrm{C} 6-\mathrm{H} \cdots \mathrm{O} 9$ contacts; the calculated charge of $\mathrm{O} 7$ is also more negative than that of $\mathrm{O} 9$, as discussed above; see Table 2); (iii) the $\nu_{3}$ (ring) band (that is in fact associated with a quite delocalized over the molecule vibration; see Table $5)$, which shifts up by ca. $20-30 \mathrm{~cm}^{-1}$.

The observed frequency shifts in the $\nu(\mathrm{NH})$ and $\gamma(\mathrm{NH})$ bands upon $\mathrm{H}$-bond formation are particularly relevant, because it has been shown before ${ }^{52,53}$ that the shift to lower frequencies of the $\mathrm{NH}$ stretching mode and the shift to higher frequencies of the corresponding out-of-the-plane $\mathrm{NH}$ rocking mode are correlated, since both parameters correlate with the H-bond energy. The empirical correlation has the form $\Delta \nu_{\gamma(\mathrm{NH})^{2}}=$ $2.5\left(\left|\Delta \nu_{\nu(\mathrm{NH})}\right|\right)^{1 / 2}-18$, where $\Delta \nu_{\gamma(\mathrm{NH})}{ }^{2}=\left(10^{-2} \nu_{\mathrm{H} \gamma(\mathrm{NH})}\right)^{2}-$ $\left(10^{-2} \nu_{0 \gamma(\mathrm{NH})}\right)^{2}$ and $\Delta \nu_{\nu(\mathrm{NH})}=\nu_{\mathrm{H} \nu(\mathrm{NH})}-\nu_{0 \nu(\mathrm{NH})}$, the subscripts " $\mathrm{H}$ " and " 0 " pertaining to $\mathrm{H}$-bonded and free molecules, respectively, and the frequencies are expressed in $\mathrm{cm}^{-1}$. For 1$\mathrm{MH}$, application of this empirical correlation using the $\nu(\mathrm{NH})$ frequency for the matrix-isolated compound as reference, led to estimated frequencies for $\gamma(\mathrm{NH})$ in the low temperature amorphous, polymorph I (at 15, $245 \mathrm{~K}$ and room temperature), polymorph II (room temperature) and liquid of 820, 823/821/ 821,808 , and $805 \mathrm{~cm}^{-1}$, respectively, which are in fairly good agreement with the experimental values: 792, 831/823/817, 771 , and $734 \mathrm{~cm}^{-1}$ (see Tables 7 and 8). Interestingly, for 1$\mathrm{MH}$ the correlation seems to apply also when the $\delta(\mathrm{NH})$ inplane bending mode is considered instead of the out-of-plane $\gamma(\mathrm{NH})$ rocking mode. In this case, the estimated frequency values using the empirical correlation are 1479, 1480/1479/ 1479,1472 , and $1470 \mathrm{~cm}^{-1}$, which compare well with the corresponding observed values: 1496, 1507/1502/1500, 1489, and $1485 \mathrm{~cm}^{-1}$.

An estimation of the $\mathrm{H}$-bond energies can also be obtained from the observed shifts in the $\mathrm{NH}$ frequencies upon hydrogen bonding. The $\mathrm{H}$-bond energy (in $\mathrm{kJ} \mathrm{mol}^{-1}$ ) and the shifts $\left(\mathrm{cm}^{-1}\right)$ in the $\nu(\mathrm{NH})$ and $\gamma(\mathrm{NH})$ bands were shown to obey 
Table 8. Observed Infrared Bands (Wavenumbers in $\mathrm{cm}^{-1}$ ) of the Amorphous Film of Neat Solid 1-MH, at $10 \mathrm{~K}$, and of the Crystalline Film of the Compound at $245 \mathrm{~K}$ (after Annealing of the Amorphous Film) and at $15 \mathrm{~K}$ (after Re-Cooling), with Assignments (Shifts in Relation to the Average Values Observed for the Matrix-Isolated Monomer Are Given in Parentheses) ${ }^{a}$

\begin{tabular}{|c|c|c|c|c|c|c|}
\hline \multirow{2}{*}{$\begin{array}{l}\text { Amorphous } \\
(10 \mathrm{~K}) \\
\text { Freq }\end{array}$} & \multirow[b]{2}{*}{ Shift $^{a}$} & \multicolumn{4}{|l|}{ Crystal } & \multirow[b]{2}{*}{ Assignment ${ }^{b}$} \\
\hline & & $\begin{array}{l}(15 \mathrm{~K}) \\
\text { Freq }\end{array}$ & Shift $^{a}$ & $\begin{array}{l}(245 \mathrm{~K}) \\
\text { Freq }\end{array}$ & Shift $^{a}$ & \\
\hline $\begin{array}{l}3184 / 3074 / \\
2801 / 2765\end{array}$ & -529 & $\begin{array}{l}3145 / 3128 / \\
3033 / 2830 / \\
2797 / 2750\end{array}$ & -537 & $\begin{array}{l}3202 / 3141 / \\
3045 / 2819 / \\
2781 / 2744\end{array}$ & -531 & $v(\mathrm{NH})$ \\
\hline 29607 & -16 & 2982 & 6 & 2983 & 7 & $v\left(\mathrm{CH}_{3}\right)_{\mathrm{as}}{ }^{\prime}$ \\
\hline 2960$\}$ & -1 & $2961\}$ & 0 & $2957\}$ & -4 & $\mathrm{v}\left(\mathrm{CH}_{3}\right)_{\mathrm{as}}{ }^{\prime \prime}$ \\
\hline 2960 J & 9 & $2961\}$ & 10 & $2957\}$ & 6 & $v\left(\mathrm{CH}_{2}\right)_{\mathrm{a}}$ \\
\hline 2927 & -3 & 2931 & 1 & 2933 & 3 & $\mathrm{v}\left(\mathrm{CH}_{2}\right)_{\mathrm{s}}$ \\
\hline 2883 & -12 & $2901 / 2886$ & -6 & 2886 & -9 & $v\left(\mathrm{CH}_{3}\right)_{\mathrm{s}}$ \\
\hline $1798 / 1774$ & -18 & 1804/ 1771 & -17 & 1801/ 1771 & -18 & $v(\mathrm{C}=\mathrm{O} 9)$ \\
\hline 1724 & -40 & $\begin{array}{l}1754 / 1724 / \\
1714 / 1695\end{array}$ & -42 & $\begin{array}{l}1748 / 1725 / \\
1711 / 1688\end{array}$ & -46 & $v(\mathrm{C}=\mathrm{O} 7)$ \\
\hline 1517 & 19 & 1517 & 19 & 1516 & 18 & $\delta\left(\mathrm{CH}_{3}\right)_{\mathrm{as}}{ }^{\prime}$ \\
\hline 1496 & 157 & 1507 & 168 & 1502 & 163 & $\delta(\mathrm{NH})$ \\
\hline 1456$\}$ & 0 & $1462 / 1459$ & 4 & 1458 & 2 & $\delta\left(\mathrm{CH}_{3}\right)_{\mathrm{as}}{ }^{\prime \prime}$ \\
\hline 1456 & 1 & $1452 / 1448$ & -5 & 1452 & -3 & $\delta\left(\mathrm{CH}_{2}\right)$ \\
\hline 1427 & -1 & 1424 & -4 & 1421 & -7 & $\delta\left(\mathrm{CH}_{3}\right)_{\mathrm{s}}$ \\
\hline 1409 & 0 & 1415 & 6 & $1417 / 1415$ & 7 & $v_{2}$ (ring) \\
\hline 1345 & 23 & 1345 & 23 & 1343 & 21 & $v_{4}(\text { ring })^{c}$ \\
\hline 1293 & -1 & $1293 / 1287$ & -4 & 1291 & -3 & $v(\mathrm{NC})$ \\
\hline 1239 & 4 & 1238 & 3 & 1237 & 2 & $\left.\mathrm{w}\left(\mathrm{CH}_{2}\right)\right)$ \\
\hline 1190 & 12 & $1199 / 1191$ & 17 & $1198 / 1191$ & 17 & $\operatorname{tw}\left(\mathrm{CH}_{2}\right)$ \\
\hline 1128 & -3 & 1123 & -8 & $1124 / 1114$ & -12 & $\gamma\left(\mathrm{CH}_{3}\right)^{\prime \prime}$ \\
\hline 1147 & 39 & 1158 & 50 & $1153 / 1145$ & 41 & $v_{1}(\text { ring })^{c}$ \\
\hline 1034 & 6 & 1044 & 16 & 1044 & 16 & $\gamma\left(\mathrm{CH}_{3}\right)^{\prime}$ \\
\hline 992 & 2 & 982 & -8 & 982 & -8 & $\gamma\left(\mathrm{CH}_{2}\right)$ \\
\hline 902 & 18 & 900 & 16 & 899 & 15 & $v_{5}$ (ring) \\
\hline 839 & 23 & 849 & 33 & 846 & 30 & $v_{3}$ (ring) \\
\hline 792 & 264 & 831 & 303 & 823 & 295 & $\gamma(\mathrm{NH})$ \\
\hline 757 & 5 & 753 & 1 & 754 & 2 & $\gamma(\mathrm{C}=\mathrm{O} 7)$ \\
\hline 694 & 6 & 703 & 15 & 702 & 14 & $\delta_{1}$ (ring) \\
\hline 598 & 10 & 602 & 14 & 601 & 13 & $\gamma(\mathrm{C}=\mathrm{O9})$ \\
\hline 574 & -14 & $571\}$ & -17 & $571\}$ & -17 & $\delta(\mathrm{C}=\mathrm{O} 7)$ \\
\hline 567 & 13 & $571\}$ & 17 & $571\}$ & 17 & $\delta_{2}$ (ring) \\
\hline
\end{tabular}

${ }^{a}$ Key: (a) When more than one band are assigned to a given mode, the shift correspond to the mean shift. (b) See Scheme 1 for atom numbering; assignments correspond to approximate descriptions of the vibrations chosen as the main coordinate contributing to the vibration (avoiding repetition) and are based on the PED's obtained for the isolated monomer (see Table 5); abbreviations: w, wagging; tw, twisting; $\gamma$, rocking; $\nu$, stretching; $\delta$, bending; $\tau$, torsion; s, symmetric; as, antisymmetric. (c) Also with a significant contribution from the $\delta(\mathrm{NH})$ coordinate.

(to within 10\%) the empirical correlations, $(\Delta H)^{2}=1.92$ $\left[\Delta \nu_{\nu(\mathrm{NH})}-40\right]$, and $-\Delta H=0.67 \times 10^{4} \times \Delta \nu_{\gamma(\mathrm{NH})}{ }^{2}$. Using these relationships, the average energies of the H-bonds present in the two polymorphs of $1-\mathrm{MH}$ at room temperature $\left(25^{\circ} \mathrm{C}\right)$ were estimated as equal to ca. -28 and $-26 \mathrm{~kJ} \mathrm{~mol}^{-1}$, respectively, i.e., H-bond networks in the two polymorphs have similar strengths. Nevertheless, though the difference between these two values is of the same order of magnitude as the uncertainty of the empirical correlation in determining absolute H-bond enthalpy values (and then cannot be taken quantitatively), the results point to an average slightly stronger H-bond network in polymorph I. Applying the same correlations to polymorph $\mathrm{I}$ at $15 \mathrm{~K}$, the resulting value is $-30 \mathrm{~kJ} \mathrm{~mol}^{-1}$, suggesting also an increase of the strength of the $\mathrm{H}$-bonding in this polymorph at lower temperatures, in agreement with the above-mentioned increased order of the crystal in these conditions that, in turn, is mostly induced by the smaller vibrational amplitudes at low temperature. By the same way, the average $\mathrm{H}$-bond energies in the low temperature 1-MH amorphous state $\left(-27 \mathrm{~kJ} \mathrm{~mol}^{-1}\right)$ and liquid phase $(-24$ $\mathrm{kJ} \mathrm{mol}^{-1}$ ) could also be estimated.

\section{CONCLUSIONS}

The FTIR spectrum of monomeric 1-MH isolated in solid argon was recorded and interpreted. Assignments of the vibrational modes were done based on DFT (B3LYP)/6-311+
$+\mathrm{G}(\mathrm{d}, \mathrm{p})$ theoretical calculations and normal coordinate analysis. The molecular structure of the compound and its detailed electronic structure in the ground state were investigated theoretically, also through natural bond orbital (NBO) and atoms in molecules (AIM) analyses. It was concluded that the minima in the potential energy surfaces of the molecule correspond to the $C_{s}$ symmetry structure. Specially interesting was the observation that NBO partial $\pi$ charge is superior in $\mathrm{O} 7$ atom than in $\mathrm{O} 9$ atom and the $\pi$ charge in $\mathrm{N} 3$ atom is superior than in $\mathrm{N} 1$ atom, facts that are intrinsically connected to $1-\mathrm{MH}$ mesomeric structures and are the result of the predominant stabilizing interaction between the molecule orbitals.

AIM analysis indicated a reduced ring strain in the molecule, with the most strained fragment corresponding to the C5C4N3C2 moiety (with $\sim 67 \%$ of the total ring strain) suggesting the elimination of isocyanic acid (specifically the fragment $\mathrm{H} 8 \mathrm{~N} 3 \mathrm{C} 4 \mathrm{O} 9$ ) as a favored fragmentation process in 1$\mathrm{MH}$. Accordingly, the $230 \mathrm{~nm}$ induced photolysis of matrix isolated $1-\mathrm{MH}$ occurs via two different pathways, which lead to fragmentation to $\mathrm{OCNH}+\mathrm{CO}+\mathrm{H}_{2} \mathrm{C}=\mathrm{NCH}_{3}$ (preferred pathway) or to $2 \mathrm{CO}+2 \mathrm{H}_{2} \mathrm{C}=\mathrm{NH}$.

The thermal analysis study allowed observation of two polymorphs of the compound, a previously reported form (I $)^{19}$ and a new form (II) which can be obtained by sublimation at $T$ $=100{ }^{\circ} \mathrm{C}, p=103 \mathrm{~Pa}$, using the coldfinger technique, with 
water at about $20{ }^{\circ} \mathrm{C}$ as the freezing fluid. This polymorph converts into polymorph I upon heating in a transition that, for the neat compound at a warming rate of $10{ }^{\circ} \mathrm{C} \mathrm{min}{ }^{-1}$, extends from about 110 to $135{ }^{\circ} \mathrm{C}$. Polymorph I can be obtained by crystallization of the low temperature amorphous phase resulting from fast deposition of the vapor of the compound onto a substrate kept at $10 \mathrm{~K}$. The IR spectra of the low temperature amorphous solid, of the two crystalline polymorphs and of the melted compound (at $165{ }^{\circ} \mathrm{C}$ ) were obtained and interpreted. From the shifts observed in the $\mathrm{NH}$ stretching, in-plane bending and out-of-plane rocking bands upon $\mathrm{H}$-bond formation (compared to the positions of the corresponding bands for the matrix-isolated molecule), the $\mathrm{H}$ bond energies in the different phases of the neat compound were estimated. At room temperature, polymorph II was found to have an average slightly weaker H-bond network than polymorph I.

\section{ASSOCIATED CONTENT}

\section{S Supporting Information}

Table S1, with internal coordinates used in the normal modes analysis of 1-methylhydantoin (1-MH); Figure S1, with electron density surfaces of selected NBOs of 1-MH, showing the dominant orbital interactions; Figure S2, with infrared spectra (3600-1600 $\mathrm{cm}^{-1}$ region) of the amorphous film of neat solid $1-\mathrm{MH}$, at $10 \mathrm{~K}$, of the crystalline film of the compound at $245 \mathrm{~K}$ and at $15 \mathrm{~K}$, and infrared spectrum of the matrix isolated monomers of 1-MH (argon matrix, $10 \mathrm{~K}$ ); Figure S3, with the X-ray powder diffractogram of the original sample of 1-MH used in this study and theoretical diffractogram for polymorph I obtained from the X-ray crystal data reported in ref 19; Figure S4, with 1-MH attenuated reflectance IR spectra $\left(3600-1600 \mathrm{~cm}^{-1}\right.$ range) of polymorphs I and II; Figure S5, with the X-ray powder diffractogram of polymorph II; and Figure S6, with infrared spectra (3600-1600 $\mathrm{cm}^{-1}$ region) of liquid $1-\mathrm{MH}$, at $165{ }^{\circ} \mathrm{C}$, and of the two crystalline polymorphs of the compound at room temperature $\left(25^{\circ} \mathrm{C}\right)$; and complete ref 22 . This material is available free of charge via the Internet at http://pubs.acs.org.

\section{AUTHOR INFORMATION}

\section{Corresponding Author}

*(R.F.) E-mail: rfausto@ci.uc.pt.

\section{Notes}

The authors declare no competing financial interest.

\section{ACKNOWLEDGMENTS}

This work was supported by the Portuguese "Fundação para a Ciência e a Tecnologia" (FCT) Research Project PTDC/QUIQUI/111879/2009, cofunded by QREN-COMPETE-UE; Coimbra LaserLab grant No. 228334 of the European Community's Seventh Framework Programme. The Coimbra Chemistry Centre is supported by the FCT through the project Pest-OE/QUI/UI0313/2014. Thanks are due to Professor Manuela Ramos Silva, Physics Department, University of Coimbra, for the X-ray powder diffraction measurements.

\section{REFERENCES}

(1) Block, S. S. Disinfection, Sterilization and Preservation, 4th ed., Lea \& Febiger Inc.: Philadelphia, USA, 2003.

(2) Kumar, C. S. A.; Kavitha, C. V.; Vinaya, K.; Prasad, S. B. B.; Thimmegowda, N. R.; Chandrappa, S.; Raghavan, S. C.; Rangappa, K. S. Synthesis and in Vitro Cytotoxic Evaluation of Novel Diazaspiro
Bicyclo Hydantoin Derivatives in Human Leukemia Cells: A SAR Study. Invest New Drugs. 2009, 27, 327-337.

(3) Kavitha, C. V.; Nambiar, M.; Kumar, C. S. A.; Choudhary, B.; Muniyappa, K.; Rangappa, K. S.; Raghavan, S. C. Novel Derivatives of Spirohydantoin Induce Growth Inhibition Followed by Apoptosis in Leukemia Cells. Biochem. Pharmacol. 2009, 77, 348-363.

(4) Sarges, R.; Schnur, R. C.; Belletire, J. L.; Peterson, M. J. Spirohydantoin Aldose Reductase Inhibitors. J. Med. Chem. 1988, 31, 230-243.

(5) Yang, K.; Tang, Y.; Iczkowski, K. A. Phenyl-methylene Hydantoins Alter CD44-Specific Ligand Binding of Benign and Malignant Prostate Cells and Suppress CD44 Isoform Expression. Am. J. Transl. Res. 2010, 2, 88-94.

(6) Park, H. S.; Choi, H. J.; Shin, H. S.; Lee, S. K.; Park, M. S. Synthesis and Characterization of Novel Hydantoins as Potential COX-2 Inhibitors: 1,5-Diarylhydantoins. Bull. Korean Chem. Soc. 2007, 28, $751-757$.

(7) Comber, R. N.; Reynolds, R. C.; Friedrich, J. D.; Manguikian, R. A.; Buckheit, R. W.; Truss, J. W.; Shannon, W. M.; Secrist, J. A. 5,5Disubstituted Hydantoins: Syntheses and Anti-HIV Activity. J. Med. Chem. 1992, 35, 3567-3572.

(8) Cruz-Cabeza, A. J.; Schwalbe, C. H; Observed and Predicted Hydrogen Bond Motifs in Crystal Structures of Hydantoins, Dihydrouracils and Uracils. New J. Chem. 2012, 36, 1347-1354.

(9) Yu, F.; Schwalbe, C. H.; Watkin, D. J. Hydantoin and Hydrogen Bonding Patterns in Hydantoin Derrivatives. Acta Crystallogr., Sect. C: Cryst. Struct. Commun. 2004, 60, 714-717.

(10) Amharar, Y.; Petit, S.; Sanselme, M.; Cartigny, Y.; Petit, M. N.; Coquerel, G. Crystal Structures, Dehydration Mechanism, and Chiral Discrimination in the Solid State of a Hydantion Derivative. Cryst. Growth Des. 2011, 11, 2453-2462.

(11) Coquerel, G.; Petit, M. N.; Robert, F. Structure of (+)-(S)-5Phenyl-5-ethylhydantoin. Acta Crystallogr., Sect. C: Cryst. Struct. Commun. 1993, 49, 824-825.

(12) Coquerel, G.; Petit, M. N. Recognition of Enantiomers through Morphology of Single Crystals; Application to Some 5-Alkyl-5-arylhydantoin Derivatives. J. Cryst. Growth. 1993, 130, 173-180.

(13) Courvoisier, L.; Mignot, L.; Petit, M. N.; Coquerel, G. Combined Effects of Polymorphism and Process on Preferential Crystallization: Example with $( \pm)-5\left(4^{\prime}\right.$ - Methylphenyl)-5-methyhyantoin. Org. Process Res. Dev. 2003, 7, 1007-1016.

(14) Allen, F. H. The Cambridge Structural Database: A Quarter of a Million Crystal Structures and Rising. Acta Crystallogr. Sect. B: Struct. Sci. 2002, 58, 380-388.

(15) Bruno, I. J.; Cole, J. C.; Edington, P. R.; Kessler, M.; Macrae, C. F.; McCabe, P.; Pearson, J.; Taylor, R. New Software for Searching the Cambridge Structural Database and Visualizing Crystal Structures. Acta Crystallogr., Sect. B: Struct. Sci. 2002, 58, 389-397.

(16) Ildiz, G. O.; Boz, I.; Unsalan, O. FTIR Spectroscopic and Quantum Chemical Studies on Hydantoin. Opt. Spectrosc. 2012, 112, $665-670$.

(17) Ildiz, G. O.; Nunes, M. C.; Fausto, R. Matrix Isolation Infrared Spectra and Photo-chemistry of Hydantoin. J. Phys. Chem. A 2013, $117,726-734$.

(18) Yu, F. L.; Schwalbe, C. H.; Watkin, D. J. Hydantoin and Hydrogen-Bonding Patterns in Hydantoin Derivatives. Acta Crystallogr., Sect. C: Cryst. Struct. Commun. 2004, 60, 714-717.

(19) Puszynska-Tuszkanow, M.; Daszkiewicz, M.; Maciejewska, G.; Staszak, Z.; Wietrzyk, J.; Filip, B.; Cieslak-Golonka, B.; HSAB, M. Principle and Nickel(II) Ion Reactivity Towards 1-Methyhydantoin. Polyhedron 2011, 30, 2016-2025.

(20) Kleinpeter, E. The Structure of Hydantoins in Solution and in the Solid State. Struct. Chem. 1997, 8, 161-173.

(21) Sabbah, R.; An, X. W.; Chickos, J. S.; Leitão, M. L. P.; Roux, M. V.; Torres, L. A. L. A. Reference Materials for Calorimetry and Differential Thermal Analysis. Thermochim. Acta 1999, 331, 93-204.

(22) Gaussian 09, Revision D.01, Frisch, M. J..; Trucks, G. W.; Schlegel, H. B.; Scuseria, G. E.; Robb, M. A.; Cheeseman, J. R.; 
Scalmani, G.; Barone, V.; Mennucci, B.; Petersson, G. A. et al. Gaussian, Inc.: Wallingford CT. 2009.

(23) Becke, A. D. Density-Functional Exchange-Energy Approximation with Correct Asymptotic Behavior. Phys. Rev. A 1988, 38, 3098-3100.

(24) Lee, C. T.; Yang, W. T.; Parr, R. G. Development of the Collesalvati Corelation Energy Formula into a Functional of Electron Density. Phys. Rev. B 1988, 37, 785-789.

(25) McLean, A. D.; Chandler, G. S. Contracted Gaussian-basis Sets for Molecular Calculations. 1. 2nd row atoms, $\mathrm{Z}=11-18$. J. Chem. Phys. 1980, 72, 5639-5648.

(26) Schachtschneider, J. H.; Mortimer, F. S. Vibrational Analysis of Polyatomic Molecules. VI. FORTRAN IV Programs for Solving the Vibrational Secular Equation and for the Least-Squares Refinement of Force Constants. Project No. 31450. Structural Interpretation of Spectra; Shell Development Co.: Emeryville, CA, 1969

(27) Pulay, P.; Fogarasi, G.; Pang, F.; Boggs, J. E. Systematic Ab Initio Gradient Calculation of Molecular Geometries, Force Constants and Dipole-moment Derivatives. J. Am. Chem. Soc. 1979, 101, 25502560.

(28) Weinhold, F.; Landis, C. R.; Valency and Bonding. A Natural Bond Orbital Donor-Acceptor Perspective; Cambridge University Press: New York. 2005.

(29) Reed, A. E.; Curtiss, L. A.; Weinhold, F. Intermolecular Interactions from a Natural Bond Orbital, Donor-acceptor Viewpoint. Chem. Rev. 1988, 88, 899-926.

(30) Bader, R. F. W.; Atoms in Molecules: A Quantum Theory, International Series of Monographs on Chemistry 22, Oxford University Press: New York, 2003.

(31) Lu, T.; Chen, F. Multiwfn: A Multifunctional Wavefunction Analyzer. J. Comput. Chem. 2012, 33, 580-592.

(32) Fox, M. A.; Whitesell, J. K. Organische Chemie: Grundlagen, Mechanismen, Bioorganische Anwendungen. Spektrum Akad. Verl.: Heidelberg, Germany, 1995.

(33) Fausto, R.; Batista de Carvalho, L. A. E.; Teixeira-Dias, J. J. C.; Ramos, M. N. s-cis and s-trans Conformers of Formic, Thioformic and Dithioformic Acids. An Ab Initio Study. J. Chem. Soc., Faraday Trans. 2 1989, 85, 1945-1962.

(34) McKean, D. C. Individual $\mathrm{CH}$ Bond Strengths in Simple Organic Compounds: Effects of Conformation and Substitution. Chem. Soc. Rev. 1978, 7, 399-422.

(35) Castiglioni, C.; Gussoni, M.; Zerbi, G. Intramolecular Electrical and Dynamical Interactions in Formaldehyde: A Discussion Based on Infrared Intensity Data. J. Chem. Phys. 1985, 82, 3534-3541.

(36) Iogansen, A. V. Direct Proportionality of the Hydrogen Bonding Energy and the Intensification of the Stretching $\nu(\mathrm{XH})$ Vibration in Infrared Spectra. Spectrochim. Acta, Part A 1999, 55, 1585-1612.

(37) Fausto, R. Bonding in Carbonyl and Thiocarbonyl Compounds: An Ab Initio Charge Density Study of $\mathrm{H}_{2} \mathrm{C}=\mathrm{X}$ and $\mathrm{HC}(=\mathrm{X}) \mathrm{YH}(\mathrm{X}, \mathrm{Y}=$ O or S). J. Mol. Struct. Theochem. 1994, 315, 123-136.

(38) Wiberg, K. B.; Laidig, K. E. Rotational Barriers Adjacent to Carbonyl Groups 3. Amide Resonance and the C-O Barrier in Acids and Esters. J. Am. Chem. Soc. 1987, 109, 5935-5943.

(39) Boyd, R. J.; Choi, S. C. Hydrogen Bonding Between Nitriles and Hydrogen Halides and the Topological Properties of Molecular Charge Distributions. Chem. Phys. Lett. 1986, 129, 62-65.

(40) Carroll, M. T.; Bader, R. F. W. An Analysis of the Hydrogen Bond in BASE-HF Complexes Using the Theory of Atoms in Molecules. Mol. Phys. 1988, 65, 695-722.

(41) Domagala, M.; Grabowski, S.; Urbaniak, K.; Mloston, G. Role of $\mathrm{C}-\mathrm{H} \cdots \mathrm{S}$ and $\mathrm{C}-\mathrm{H} \cdots \mathrm{N}$ Hydrogen Bonds in Organic Crystal Structures-The Crystal and Molecular Structure of 3-Methyl-2,4diphenyl-(1,3)-thiazolidine-5-spiro-2'-adamantane and 3-Methyl2,4,5,5-tetra-phenyl-(1,3)-thiazolidine. J. Phys. Chem. A 2003, 107, $2730-2736$.

(42) Grabowski, S.; Sokalski, W. A.; Leszczynski, J. How Short Can the $\mathrm{H} \cdots \mathrm{H}$ Inter-molecular Contact Be? New Findings that Reveal the Covalent Nature of Extremely Strong Interactions. J. Phys. Chem. A 2005, 109, 4331-4341.
(43) Domagala, M.; S. Grabowski, S. CH $\cdots \mathrm{N}$ and $\mathrm{CH} \cdots \mathrm{S}$ Hydrogen Bonds Influence of Hybridization on Their Strength. J. Phys. Chem. A 2005, 109, 5683-5688.

(44) Teles, J. H.; Maier, G.; Hess, B. A., Jr.; L, J.; Schaad, L. J.; Winnewisser, M.; Winnewisser, B. P. The CHNO Isomers. Chem. Ber. 1989, 122, 753-766.

(45) Abe, H.; Takeo, H.; Yamada, K. M. T. Infrared Spectroscopy of CO Trapped in an Argon Matrix Revisited. Chem. Phys. Lett. 1999, 311, 153-158.

(46) Halonen, L.; Duxbury, G. Fourier Transform Infrared Spectrum of $\mathrm{CH}_{2} \mathrm{NH}$ : The $\nu_{1}$ Band. Chem. Phys. Lett. 1985, 118, 246-251.

(47) Gómez-Zavaglia, A.; Reva, I. D.; Frija, L.; Cristiano, M. L.; Fausto, R. Molecular Structure, Vibrational Spectra and Photochemistry of 2-Methyl-2H-tetrazol-5-amine in Solid Argon. J. Phys. Chem. A 2005, 109, 7967-7976.

(48) Oliveira, G. D.; Martin, J. M. L.; Silwal, I. K. C.; Liebman, J. F. Definitive Heat of Formation of Methylenimine, $\mathrm{CH}_{2} \mathrm{NH}$, and of Methylenimmonium Ion, $\mathrm{CH}_{2} \mathrm{NH}_{2}{ }^{+}$, by Means of W2 Theory. J. Comput. Chem. 2001, 22, 1297-1305.

(49) Shen, J. X.; Brodbelt, J. Ion-Molecule Reactions of Hydantoin and Succinimide Anticonvulsants with Dimethyl Ether Ions in a Quadrupole Ion Trap Mass Spectrometer. J. Mass Spectrom. 1996, 31, $1389-1398$

(50) Corral, R. A.; Orazi, O. O.; Duffield, A.; Djerassi, M. C. Mass Spectrometry in Structural and Stereochemical Problems CCIV. Spectra of Hydantoins II. Electron Impact Induced Fragmentation of Some Substituted Hydantoins. Org. Mass Spectrom. 1971, 5, 551-567.

(51) Schoch, S.; Blos, I.; Rüdiger, W. Die Massenspektren Substituierter Succinimide. Org. Mass Spectrom. 1975, 10, 797-807.

(52) Rozenberg, M. S. IR Spectra and Hydrogen Bond Energies of Crystalline Acid Salts of Carboxylic Acids. Spectrochim. Acta, Part A 1996, 52, 1559-1709.

(53) Rozenberg, M. S.; Shoham, G.; Reva, I.; Fausto, R. Low Temperature FTIR Spectroscopy and Hydrogen Bonding in Cytosine Polycrystals. Spectrochim. Acta, Part A 2004, 60, 463-470. 